\title{
Review Article \\ The Complementary and Alternative Medicine for Endometriosis: A Review of Utilization and Mechanism
}

\author{
Sai Kong, ${ }^{1}$ Yue-Hui Zhang, ${ }^{2,3}$ Chen-Fang Liu, ${ }^{1}$ Ilene Tsui, ${ }^{4}$ Ying Guo, ${ }^{1}$ \\ Bei-Bei Ai, ${ }^{1}$ and Feng-Juan Han $^{2}$ \\ ${ }^{1}$ Department of Obstetrics and Gynecology, Heilongjiang University of Chinese Medicine, Harbin 150040, China \\ ${ }^{2}$ Department of Obstetrics and Gynecology, The First Affiliated Hospital of Heilongjiang University of Chinese Medicine, \\ Harbin 150040, China \\ ${ }^{3}$ Center for Post-Doctoral Studies, Heilongjiang University of Chinese Medicine, Harbin 150040, China \\ ${ }^{4}$ Pennsylvania State University College of Medicine, Hershey, PA 17033, USA
}

Correspondence should be addressed to Feng-Juan Han; hanfengjuan2004@163.com

Received 9 September 2013; Accepted 6 January 2014; Published 19 February 2014

Academic Editor: Xiaoke Wu

Copyright (C) 2014 Sai Kong et al. This is an open access article distributed under the Creative Commons Attribution License, which permits unrestricted use, distribution, and reproduction in any medium, provided the original work is properly cited.

\begin{abstract}
Endometriosis (EM) is one of the common gynecological conditions causing menstrual and pelvic pain and affects $10 \%-15 \%$ of women of reproductive age. In recent years, the complementary and alternative medical (CAM) treatment for EM has become popular due to the few adverse reactions reported. The CAM therapy for EM includes several different treatments such as herbs (herbal prescription, extract, and patent), acupuncture, microwave physiotherapy, and Chinese herb medicine enema (CHM enema). These CAM therapies are effective at relieving dysmenorrhoea, shrinking adnexal masses, and promoting pregnancy, with less unpleasant side effects when compared to hormonal and surgical treatments. In this review, we focus on the status quo of CAM on EM and try to identify therapeutic efficacy and mechanisms based on some clinical and experimental studies. We hope to provide some instructive suggestions for clinical treatment and experimental research in the future.
\end{abstract}

\section{Introduction}

Endometriosis (EM) is a chronic, estrogen-dependent disorder and therefore generally occurs when endometrial tissue grows abnormally and adheres outside of the uterus. EM has a high prevalence rate in women of reproductive age and is divided into ovarian EM, peritoneal EM, and deep infiltrating EM according to the sites of implantation. The most common site is the ovary and the most common symptom is chronic pelvic pain, notably dysmenorrhoea, dyspareunia, and infertility, which all may lead to a reduction in the patient's quality of life. EM rarely undergoes malignant transformation, but with it there is a rising risk of ovarian, breast, and other cancers as well as autoimmune and atopic disorders [1]. The exact pathogenic mechanisms of EM remain unknown since Von Rokitonsky proposed the term "EM" in 1860 [2]; though recently, researchers propose several theories, including implantation theory, coelomic epithelium metaplasia theory, and induction theory. Research continues to examine other risk factors which may be potentially involved in the formation of EM, including genetics [3], immune factors [4], inflammatory factors [5], eutopic endometrium specificity, and environmental toxins [6] (Figure 1).

Treatment for EM can be medical and/or surgical. In western medicine, hormone replacement therapy is commonly used and involves oral contraceptives, progesto genics, gestrinone, Danazol (androgen derivates), and gonadotropin-releasing hormone $(\mathrm{GnRH})$ agonists. Current investigations are also evaluating the role of $\mathrm{GnRH}$ antagonists, estrogen receptor beta $(\mathrm{ER} \beta)$ agoinist, progesterone receptor modulators, angiogenesis inhibitors, aromatase inhibitors, COX-2 (Cyclooxygenase 2) selective inhibitors, and immune modulators [7]. However, long-term administration with these therapies remains challening due to the plethora of serious adverse effects involved, such as massive hemorrhage, perimenopausal stage symptoms, masculinizing manifestation, and liver dysfunction. Data from the Cleveland Clinic showed that EM recurrence rate ranged between 


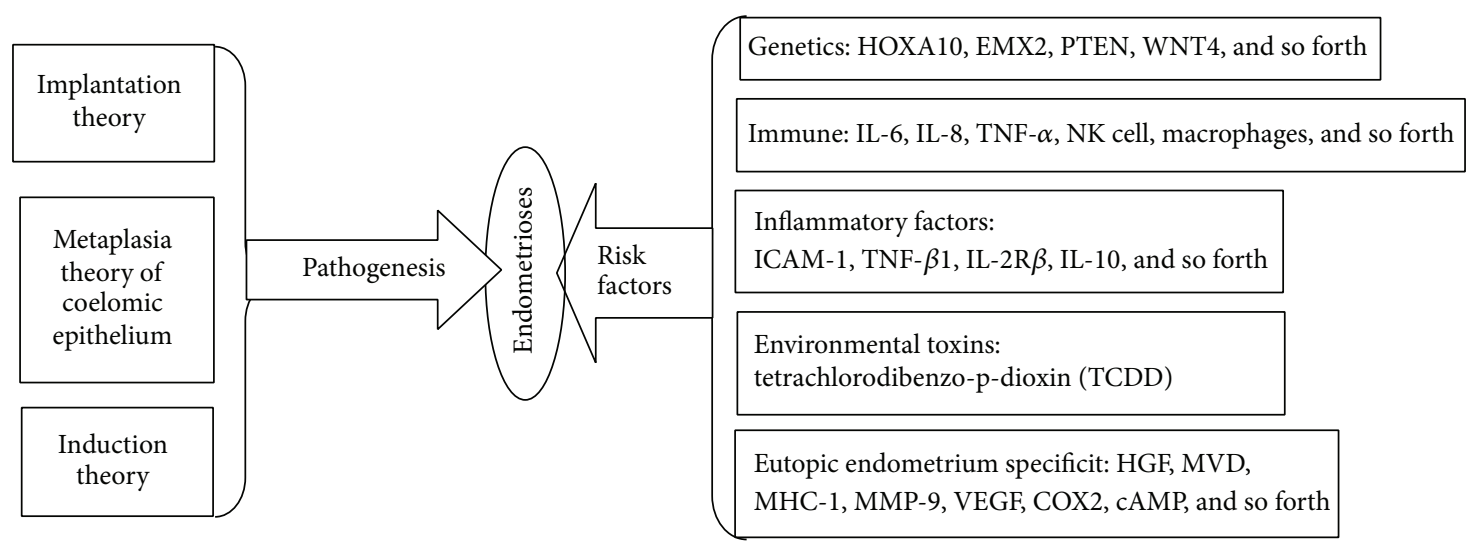

FIgURE 1: Pathogenesis and risk factors of endometriosis.

20 and 40 percent within five years following conservative surgery, unless patients reached menopause, or hysterectomy was performed [8]. With this in mind, it is important to continue looking for other strategies to treat EM that may result in less adverse side effects.

Complementary and alternative medicine (CAM), commonly designated as "other than" conventional medicine, differs from medical mainstream, is widely accepted as a kind of medical treatment, and encompasses all health systems, practices, and modalities and their accompanying beliefs, theories, and attitude of a particular culture or society in a given historical period, as defined in the 1995 CAM Research Methodology Conference. Most therapies of CAM can be considered as part of five broad classes: biological based approaches, energy therapies, alternative medical systems, muscle and joint manipulation, and mind body therapies [9]. In most Asian countries, CAM is historic and has been widely utilized since the 19th century, while utilization in western countries has continued to increase $[10,11]$.

CAM is usually suggested as available complementary therapies. Among CAM, the nonpharmacologic interventions can reduce pain and concomitant mood disturbance to increase quality of life by employing mind-body interventions [12]. In the western world, CAM is predominantly used to treat or prevent musculoskeletal conditions or other conditions associated with chronic or recurring pain [13]. Additionally, CAM therapies are often utilized, attempting to manage chronic pain [14]. All these features show that CAM is fit for pain alleviation. As EM is typically accompanied by chronic pelvic pain and dysmenorrhoea, CAM therapies could be an effective treatment strategy. The CAM therapies for EM and its mechanisms in the published literature mainly include herbal products, acupuncture, microwave physiotherapy, CHM enema, and psychological interventions (Table 1). This review will focus on the status quo of CAM therapies and mechanism on EM.

\section{Herbal Products Treatment on Endometriosis}

Herbal products typically involve the use of herbal formulae of between 10 and 20 separate herbal ingredients selected from a Materia Medica of several hundred common herbs that are prepared either as a boiled decoction, as dried herbal extracts, or taken as pills or capsules (patent). Tables 2, 3, and 4 list the most commonly used herbs for EM [15-22]. Researchers evaluated the potential application and mechanism of herbal products on EM from these aspects: (1) clinical parameters including endometriotic lesion size measured by ultrasound examination; (2) pelvic pain and dysmenorrhoea measured by determination of clinical pain visual analogue scale (VAS) method; (3) laboratory parameters including some related molecules with immune regulation, antiangiogenesis, anti-inflammatory, and cell proliferation suppression factors; (4) implanted endometrium size measured by weight and volume in EM models.

2.1. Herbal Decoction Therapies and Mechanisms on Endometriosis. There are several common decoctions used to treat EM in China, including Xuefu Zhuyu decoction (XZD), Xiaochaihu decoction (XCHD), Qu Yi Kang (QYK), Yi Wei Ning (YWN), Yi Wei San (YWS), and Huoxue Xiaoyi decoction (HXD). XZD originated from 19th century in China and has been widely used to treat EM since 1983 [23]. Some studies have shown that XZD can relieve dysmenorrhoea, shrink ectopic lesions, and promote fertility; the average therapeutic effectiveness has been greater than $90 \%$ throughout the past 30 years $[24,25]$. A clinical trial showed that XZD could relieve dysmenorrhoea as effectively as Mifepristone tablets, with the total effective rate being $90 \%$ and $73 \%$ in the XZD group and Mifepristone group, respectively, after 3 months of treatment with a study group of 120 patients [26]. Similar results were observed with a clinical trial of 42 patients treated with XZD for 6 months. Results showed that 5 of the $10 \mathrm{EM}$ patients with infertility were pregnant and that 25 of the $42 \mathrm{EM}$ patients were relieved of their pelvic pain [27]. Another trial [28] showed that the endometriotic lesions' size was both significantly reduced in XZD group and Danazol group, the total effective rate was $95.2 \%$ and $75.0 \%$, respectively, and $23.6 \%$ of patients were pregnant in the $\mathrm{XDZ}$ group.

$X C H D$. has been widely used to treat a variety of disorders in ancient China since the Han dynasty. Some studies showed 
TABLE 1: General view of all therapeutic approaches.

\begin{tabular}{|c|c|c|c|c|}
\hline $\begin{array}{l}\text { Therapeutic } \\
\text { approaches }\end{array}$ & Clinical indication & Specifications & Efficacy & Precautions \\
\hline Herbal products & $\begin{array}{l}\text { EM with chronic } \\
\text { pelvic pain, } \\
\text { dysmenorrhea, and } \\
\text { infertility }\end{array}$ & $\begin{array}{l}\text { According to TCM practitioners' } \\
\text { judgment of the disease, propose } \\
\text { appropriate TCM prescriptions }\end{array}$ & $\begin{array}{l}\text { Alleviate } \\
\text { dysmenorrhoea } \\
\text { Shrink endometriotic } \\
\text { lesion } \\
\text { Promote pregnancy } \\
\text { Reduce recurrence } \\
\text { rate }\end{array}$ & $\begin{array}{l}\text { Patients who are } \\
\text { allergic to some foods } \\
\text { and pollen should } \\
\text { take the herbal } \\
\text { products with caution }\end{array}$ \\
\hline $\begin{array}{l}\text { Acupuncture and } \\
\text { Moxibustion }\end{array}$ & $\begin{array}{l}\text { EM with chronic } \\
\text { pelvic pain, } \\
\text { dysmenorrhea, and } \\
\text { infertility }\end{array}$ & $\begin{array}{l}\text { Take the appropriate acupoints and } \\
\text { choose needling, auricular point, or } \\
\text { moxa-moxibustion therapy, according } \\
\text { to the disease status of patient. } 30 \mathrm{~min} \\
\text { is a course of treatment for } \\
\text { acupuncture (needling, auricular } \\
\text { point); } 40-50 \text { min is a course of } \\
\text { treatment for moxibustion }\end{array}$ & $\begin{array}{l}\text { Alleviate } \\
\text { dysmenorrhoea } \\
\text { Promote pregnancy }\end{array}$ & $\begin{array}{l}\text { Some patients may } \\
\text { occur fainting } \\
\text { condition }\end{array}$ \\
\hline CHM enema & $\begin{array}{l}\text { EM with chronic } \\
\text { pelvic pain, } \\
\text { dysmenorrhea, and } \\
\text { infertility }\end{array}$ & $\begin{array}{l}\text { Ask the patient to take the left lateral } \\
\text { decubitus position. Put the boiled } \\
\text { TCM herbal liquid into } 20 \mathrm{~mL} \text { syringe, } \\
\text { with the temperature of } 38 \sim 40^{\circ} \mathrm{C} \text {. } \\
\text { With a disposable catheter connection, } \\
\text { slowly push TCM herbal liquid into } \\
\text { the rectum. Tell the patient to relax } \\
\text { and keep the TCM herbal liquid more } \\
\text { than } 2 \text { hours }\end{array}$ & $\begin{array}{l}\text { Alleviate } \\
\text { dysmenorrhoea } \\
\text { Shrink endometriotic } \\
\text { lesion }\end{array}$ & $\begin{array}{l}\text { Unfit for predominant } \\
\text { irritable bowel } \\
\text { syndrome patients }\end{array}$ \\
\hline $\begin{array}{l}\text { Microwave } \\
\text { physiotherapy }\end{array}$ & nonacute phase of EM & $\begin{array}{l}\text { Ask the patient to take supine position. } \\
\text { Put the microwave physiotherapy } \\
\text { instrument facing patient's lower } \\
\text { abdomen, with the distance of } \\
35-45 \mathrm{~cm} .30 \text { min is a course of } \\
\text { treatment }\end{array}$ & $\begin{array}{l}\text { Alleviate } \\
\text { dysmenorrhoea } \\
\text { Shrink endometriotic } \\
\text { lesion }\end{array}$ & $\begin{array}{l}\text { Attention to operating } \\
\text { time, adjusting the } \\
\text { distance of microwave } \\
\text { physiotherapy } \\
\text { equipment, so as not } \\
\text { to scald patients }\end{array}$ \\
\hline
\end{tabular}

that XCHD could reduce the serum estradiol (E2) level and decrease the expression of $\mathrm{P} 450$ aromatase protein and COX2 protein in endometriotic tissue in the rat EM model. XCHD may play a key role in selectively inhibiting the expression of aromatase protein and COX-2 protein in EM tissues [29]. It is a feature that increased expression of proinflammatory cytokines such as tumor necrosis factor alpha (TNF- $\alpha$ ) and interleukin 8 (IL-8) in peritoneal fluid of both EM patient and animal model $[30,31]$. TNF- $\alpha$ plays an important role in the severity of EM-related dysmenorrhoea [32]. In a rat model receiving $\mathrm{XCHD}$ treatment, the volume of endometriotic lesion was significantly reduced concurrently with a reduction in the levels of IL-8, TNF- $\alpha$, and vascular endothelial growth factor (VEGF) within serum and peritoneal fluid $[33,34]$. Some researchers showed that XCHD could directly inhibit the growth of the ectopic endometrium in rat models by increasing Fas protein expression and promoting apoptosis in ectopic endometrial tissues [35-37].

QYK. is an empirical recipe which could alleviate the symptom of dysmenorrhoea by up to $90 \%$ and shrink the endometriotic lesion in up to $86.67 \%$ of patients with EM [38]. IL-2 and IL-6 play an important role in the cytokine network; the level of IL-2 reflects changes of the immune function; the level of IL-6 leads to local pelvic adhesions, fibrosis, and immunological abnormalities by mediating immune and inflammatory responses, thus contributing to the development of EM. Some studies found that QYK could reduce the levels of IL-2 and IL-6 in peritoneal fluid, inhibit the growth and proliferation of endometriotic tissue in rat EM models, and eliminate the new vascular networks on the surface of ectopic endometrium by reducing the expression of VEGF protein within the endometriotic tissue of the rat EM models. Furthermore, QYK could obviously reduce the estrogen receptor (ER) protein expression within endometrium and ectopic endometrium tissues, decreasing the amount of endometrium glands and reducing the endometriotic lesion of rat EM models [39-44].

One study showed that YWN can significantly shrink the endometrial lesion and relieve dysmenorrhoea by up to 93.48\% for EM patients [45]. Some researchers indicated that YWN could facilitate apoptosis and inhibit proliferation of ectopic endometrium by improving the expression of Fas/FasL (Fas ligand) gene and B-celllymphoma-2 (Bcl-2) associated $\mathrm{X}$ protein (bax), reducing the expression of $\mathrm{Bcl}$ 2 and Cyclo-oxygenase-2 (COX-2) mRNA in endometriotic tissues of animal EM models [46-48].

Some studies indicated that serum 6-keto-prostaglandin Fl $\alpha$ (6-keto-PGF1 $\alpha$ ) and Thromboxane B2 (TXB2) within plasma were higher in endometriotic tissues than normal 
TABLE 2: Ingredients of herbal preparations.

\begin{tabular}{|c|c|}
\hline Herbal mixture & Ingredients \\
\hline $\begin{array}{l}\text { Xuefu Zhuyu decoction } \\
\text { (XZD) }\end{array}$ & 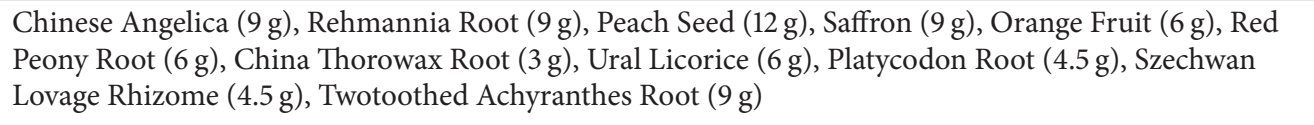 \\
\hline $\begin{array}{l}\text { Xiaochaihu decoction } \\
\text { (XCHD) }\end{array}$ & $\begin{array}{l}\text { China Thorowax Root ( } 30 \mathrm{~g}) \text {, Baical Skullcap Root (18 g), Ginseng (18 g), Pinellia Tuber (18 g), Ural } \\
\text { Licorice (18 g), Fresh Ginger (18 g), Chinese Date (12 g) }\end{array}$ \\
\hline Qu Yi Kang (QYK) & $\begin{array}{l}\text { Chinese Angelica (12 g), Red Peony Root (15 g), Szechwan Lovage Rhizome (10 g), Yanhusuo Tuber (15 g), } \\
\text { Common Burreed Tuber (10 g), Aeruginous Turmeric Rhizome (10 g), Frankincense (9 g), Myrrha (9 g), } \\
\text { Cassia Twig (9 g), Danshen Root (15 g), Cattail Pollen (10 g), Draconis Resin (6 g), Tangerine Seed (10 g) }\end{array}$ \\
\hline Yi Wei Ning $(Y W N)$ & $\begin{array}{l}\text { Red Peony Root ( } 20 \mathrm{~g}) \text {, China Thorowax Root (10 g), Aeruginous Turmeric Rhizome (15 g), Yanhusuo } \\
\text { Tuber (15 g), Centipede (2), Baical Skullcap Root (15 g), Honeysuckle Flower ( } 30 \mathrm{~g}) \text {, Coix Seed ( } 20 \mathrm{~g}) \text {, } \\
\text { Largeleaf Gentian Root (15 g), Oyster Shell (10 g) }\end{array}$ \\
\hline Yi Wei San (YWS) & $\begin{array}{l}\text { Draconis Resin ( } 30 \mathrm{~g}) \text {, Sanchi ( } 30 \mathrm{~g}) \text {, Coix Seed ( } 240 \mathrm{~g}) \text {, Appendiculate Cremastra Pseudobulb ( } 240 \mathrm{~g}) \text {, } \\
\text { Myrrha ( } 80 \mathrm{~g}) \text {, Danshen Root (120 g), Thunberg Fritillary Bulb (150 g), Red Peony Root (150 g) }\end{array}$ \\
\hline $\begin{array}{l}\text { Huoxue Xiaoyi decoction } \\
(\mathrm{HXD})\end{array}$ & Danshen Root, Red Peony Root, Aeruginous Turmeric Rhizome \\
\hline Patent medicine & Ingredients \\
\hline $\begin{array}{l}\text { Guizhi Fuling Capsules } \\
\text { (GFC) }\end{array}$ & Ramulus Cinnamomi, Poria, Cortex Moutan, Radix Paeoniae Rubra, Semen Persicae \\
\hline $\begin{array}{l}\text { Sanjie Zhentong Capsules } \\
\text { (SZC) }\end{array}$ & Resina Draconis, Radix Notoginseng, Fritillaria thunbergii, Semen Coicis \\
\hline $\begin{array}{l}\text { Dahuang Zhechong Wan } \\
\text { (DZW) }\end{array}$ & $\begin{array}{l}\text { Rhubarb (300 g), Ground Beetle ( } 30 \mathrm{~g}) \text {, Leech ( } 60 \mathrm{~g}) \text {, Gadfly ( } 45 \mathrm{~g}) \text {, Northeast Giant Black Chafer ( } 45 \mathrm{~g}) \text {, } \\
\text { Dried Lacquer ( } 30 \mathrm{~g}) \text {, Peach Seed (120 g), Bitter Apricot Kernel (120 g), Baical Skullcap Root (60 g), } \\
\text { Rehmannia Root ( } 300 \mathrm{~g}) \text {, White Peony Root (120 g), Ural Licorice ( } 90 \mathrm{~g})\end{array}$ \\
\hline $\begin{array}{l}\text { Yiweikang Granule } \\
\text { (YWKG) }\end{array}$ & $\begin{array}{l}\text { Milkvetch Root }(15 \mathrm{~g}) \text {, Cassia Twig }(10 \mathrm{~g}) \text {, Peach Seed }(10 \mathrm{~g}) \text {, Saffron }(10 \mathrm{~g}) \text {, Yanhusuo Tuber }(10 \mathrm{~g}) \text {, Leech } \\
(5 \mathrm{~g}) \text {, Szechwan Lovage Rhizome }(10 \mathrm{~g}) \text {, Immature Tangerine Peel }(10 \mathrm{~g}) \text {, Trogopterus Dung (10 g), Cattail } \\
\text { Pollen (6 g), Common Fennel (10 g), Combined Spicebush Root (10 g) }\end{array}$ \\
\hline Xiang Leng Wan (XLW) & $\begin{array}{l}\text { Peach Seed (12 g), Common Burreed Tuber }(10 \mathrm{~g}) \text {, Aeruginous Turmeric Rhizome (10 g), Tree Peony Root } \\
\text { Bark (12 g), Red Peony Root (12 g), Cassia Twig (12 g), Common Aucklandia Root (12 g), Immature } \\
\text { Tangerine Peel (12 g), Orange Fruit (12 g), Szechwan Chinaberry Fruit (12 g), Common Fennel (10 g), } \\
\text { Indian Bread (12 g) }\end{array}$ \\
\hline TCM enema & Ingredients \\
\hline $\begin{array}{l}\text { Private customized TCM } \\
\text { enema decoction }\end{array}$ & $\begin{array}{l}\text { Common Burreed Tuber }(10 \mathrm{~g}) \text {, Red Peony Root }(12 \mathrm{~g}) \text {, Aeruginous Turmeric Rhizome }(9 \mathrm{~g}) \text {, Turmeric } \\
\text { Root Tuber }(10 \mathrm{~g}) \text {, Peach Seed }(10 \mathrm{~g}) \text {, Degelatined Deer-horn }(12 \mathrm{~g}) \text {, Malaytea Scurfpea Fruit }(9 \mathrm{~g}) \text {, Cassia } \\
\text { Twig (10 g), Ground Beetle }(8 \mathrm{~g}) \text {, inner membrane of chicken gizzard (15 g) }\end{array}$ \\
\hline $\begin{array}{l}\text { Private customized TCM } \\
\text { enema decoction }\end{array}$ & $\begin{array}{l}\text { Common Burreed Tuber (10 g), Aeruginous Turmeric Rhizome (10 g), Sargentodoxa cuneata (15 g), } \\
\text { Chinese Honeylocust Spine (15 g), Honeycomb (10 g), Red Peony Root (15 g), Peach Seed (10 g) }\end{array}$ \\
\hline Qing Yi decoction & $\begin{array}{l}\text { Danshen Root ( } 20 \mathrm{~g}) \text {, Bulb Thunberg Fritillary (10 g), Frankincense (6 g), Myrrha (6 g), Sargentodoxa } \\
\text { cuneata ( } 30 \mathrm{~g}) \text {, Patrinia (15 g), Cassia bark (6 g), Yanhusuo (12 g), Tuber (12 g), Red Peony Root (12 g), } \\
\text { Chinese Angelica (12 g), Peach Seed (10 g) }\end{array}$ \\
\hline Acupoint injection TCM & Ingredients \\
\hline Xiao Qiao decoction & $\begin{array}{l}\text { Danshen Root (20 g), Common Burreed Tuber (10 g), Aeruginous Turmeric Rhizome (10 g), Chinese } \\
\text { Lobelia ( } 20 \mathrm{~g}) \text {, Spreading Hedyotis ( } 20 \mathrm{~g}) \text {, Baikal Skullcap ( } 30 \mathrm{~g}) \text {, Bulb Thunberg Fritillary (10 g), Oyster } \\
\text { Shell (30 g), Yanhusuo (10 g), Teasel ( } 10 \mathrm{~g}) \text {, Shorthorn Barrenwort (10 g), Honeylocust Spine ( } 30 \mathrm{~g})\end{array}$ \\
\hline
\end{tabular}

tissues, with 6-keto PGF1 $\alpha$ inducing the severe dysmenorrhoea. YWS can decrease the levels of TXB2 and 6-ketoPGF1 $\alpha$ within plasma in the endometriotic tissues, improving blood rheology and reducing the level of vasoactive substances as Danazol [49-52]. ICAM-1, an adhesion molecule of the immunoglobulin superfamily, plays a key role in regulating cell adhesion. Abnormal expression of ICAM-1 can promote the growth and metastasis of endometrial cells. In addition, MMP-9 also takes part in the regulation of cell adhesion and neovascularization [53]. HXD may downregulate the pathway of adhesion-aggression-angiogenesis, inhibiting the adhesion, aggression, and local angiogenesis by decreasing the expressions of ICAM-1, MMP-9, and VEGF. HXD exhibited a preferable and durable efficacy on recurrent EM treatment in rat models $[54,55]$.

Other Herbal Decoction Therapies and Mechanisms on Endometriosis. In China, several herbal mixtures are used to treat EM every year and demonstrate positive reports. For example, Cai Shi Nei Yi Fang could decrease the levels of IL-2 in the peritoneal fluid of rat EM models, while decreasing the levels of TNF- $\alpha$ in serum of rat EM models, 
TABLE 3: Herbal mixture for EM treatment in the literature.

\begin{tabular}{|c|c|c|c|c|c|}
\hline $\begin{array}{l}\text { Herbal mixture; } \\
\text { sample/case number } \\
(n)\end{array}$ & $\begin{array}{l}\text { Control; sample } \\
\text { number }(n)\end{array}$ & $\begin{array}{l}\text { Total clinical effect } \\
\text { rate }\end{array}$ & Model used & Therapeutic effects and actions & References \\
\hline $\begin{array}{l}\text { Xuefu Zhuyu } \\
\text { decoction (XZD); } \\
n=79\end{array}$ & $\begin{array}{c}\text { Gestrinone } \\
\text { Capsule; } n=56\end{array}$ & $\begin{array}{c}T: 91.14 \% \text { versus } \\
91.07 \%\end{array}$ & Human study & $\begin{array}{l}\text { Alleviate dysmenorrhoea } \\
\text { Shrink endometriotic lesion }\end{array}$ & {$[25]$} \\
\hline $\mathrm{XZD} ; n=60$ & $\begin{array}{l}\text { Mifepristone } \\
\text { Tablets; } n=60\end{array}$ & $\begin{array}{c}D: 90.0 \% \text { versus } \\
70.0 \%\end{array}$ & Human study & Alleviate dysmenorrhoea & {$[26]$} \\
\hline $\mathrm{XZD} ; n=42$ & & $\begin{array}{c}T: 93 \% ; D: 60 \% ; P: \\
12 \%\end{array}$ & Human study & $\begin{array}{l}\text { Alleviate dysmenorrhoea } \\
\text { Promote pregnancy }\end{array}$ & {$[27]$} \\
\hline $\mathrm{XZD} ; n=42$ & Danazol; $n=28$ & $\begin{array}{c}T: 95.2 \% \text { versus } \\
75.0 \% \\
P \text { in XZD: } 23.6 \%\end{array}$ & Human study & $\begin{array}{l}\text { Alleviate dysmenorrhoea } \\
\text { Promote pregnancy }\end{array}$ & {$[28]$} \\
\hline $\begin{array}{l}\text { Xiaochaihu decoction } \\
\text { (XCHD) }\end{array}$ & Danazol & & SD rat model & $\begin{array}{c}\text { COX- } 2 \downarrow \text { P450arom } \downarrow \text { Estradiol } \downarrow \\
\text { IL- } 8 \downarrow \text { TNF- } \alpha \downarrow \text { MVD } \downarrow \text { VEGF } \downarrow \\
\text { Fas protein } \uparrow \text { apoptosis } \uparrow \text { in } \\
\text { ectopic endometrial tissues }\end{array}$ & {$[29,33-37]$} \\
\hline Qu Yi Kang (QYK) & Danazol & & $\mathrm{SD}$ rat model & TXB $2 \downarrow$ IL-2 $\downarrow$, IL-6 $\downarrow$ VEGF $\downarrow$ ER $\downarrow$ & {$[39,40,42-44]$} \\
\hline $\begin{array}{l}\text { Yi Wei Ning (YWN); } \\
n=46\end{array}$ & & $T: 93.48 \%$ & Human study & $\begin{array}{l}\text { Dysmenorrhoea alleviation } \\
\text { Shrink endometriotic lesion }\end{array}$ & {$[45]$} \\
\hline YWN & & & $\begin{array}{l}\text { Wistar rat } \\
\text { model }\end{array}$ & $\begin{array}{c}\text { Fas } / \text { FasL } \uparrow \text { Bcl- } 2 \downarrow \text { Bax } \uparrow \\
\text { apoptosis } \uparrow \text { COX- } 2 \downarrow \text { in ectopic } \\
\text { endometrial tissues }\end{array}$ & {$[46,48,51]$} \\
\hline Yi Wei San (YWS) & Danazol & & Rabbit model & $\begin{array}{c}\text { 6-keto-PGF } 1 \alpha \downarrow \text { TXB } 2 \downarrow \text { Blood } \\
\text { rheology } \uparrow \text { Vasoactive } \\
\text { substances } \downarrow\end{array}$ & {$[51,52]$} \\
\hline $\begin{array}{l}\text { Huoxue Xiaoyi } \\
\text { decoction (HXD) }\end{array}$ & & & $\mathrm{SD}$ rat model & $\begin{array}{c}\text { ICAM- } 1 \downarrow \text { MMP-9 } \downarrow \text { VEGF } \downarrow \text { AAA } \\
\text { pathway } \downarrow \text { Recurrence rate } \downarrow\end{array}$ & {$[54,55]$} \\
\hline
\end{tabular}

thereby playing a role in immune regulation [56]. After treatment with Neiyi Zhitong decoction, the endometriotic lesions of the rat EM models were significantly reduced, with individual lesions minimized to only traces; the weight and volume of ectopic endometrium in rats were also reduced [57]. Neiyi Zhitong decoction could also reduce the levels of serum CA125 and regulate serum prostaglandin $\mathrm{F} 2 \mathrm{a}$ (PGF2a), prosta-glandin2 (PGE2) concentration, alleviating dysmenorrhoea [58]. Fuzheng Huayu decoction has also been shown to be comparable to western tables in reducing EM symptoms as the total effective rate was up to $73.33 \%$ in one study compared with $76.67 \%$ for Gestrinone capsules [59]. Huazhuo Jiedu Huoxue Recipe may decrease plasma Orphanin FQ (OFQ), PGF2 $\alpha$, and PGE2 contents, thereby alleviating dysmenorrhoea and pelvic pain [60]. After 6 months of treatment with Yi Kun decoction, the total effective rate of the $92 \mathrm{EM}$ patients was $91 \%$, and $92 \%$ in the Danazol control group [61]. Juan Tong Yin lowered the level of IL-6 in ascitic fluid of white rabbit EM models, regulating the immune function, so as to improve the pelvic microenvironment, thus helping to prevent EM symptoms [62]. Xianji Pill did well in reducing the severity of dysmenorrhoea and shortened the frequency of dysmenorrhoea through the observation of $70 \mathrm{EM}$ patients in one study; the total effective rate was $87.14 \%$ and $67.19 \%$ in the Xianji Pill treatment group and Danazol treatment group [63].
Wenshen Xiaozheng Tang (WXT) suppressed the growth of endometriotic lesions, partially through its antiangiogenic activity by lowering vascular density and reducing mRNA expression of hypoxia inducible factor- $1 \alpha$ (HIF- $1 \alpha$ ) of the endometriotic lesions, decreasing concentration of VEGF in peritoneal fluid of WXT-treated rats [64]. WXT could also inhibit the production of proinflammatory cytokines and regulate the expression of invasion-related genes in the endometriotic lesions, thereby suppressing the development of EM [65]. As there are various herbal mixtures, only the most commonly used ones are discussed in this section.

\subsection{Herbal Extracts Therapies and Mechanisms on Endomet-} riosis. In recent years, several herbal extracts have been commonly used to EM treatment in China, including tripterygium wilfordii polyglycoside (Twp), puerarin, turmeric, reseratrol, green tea epigallocatechin-3-gallate (EGCG), ginsenoside Rg3, and so on. Tripterygium Wilfordii polyglycoside (TWP) is an herbal extract derived from Tripterygium, a Chinese herb, and made into oral TWP tablets. TWP is widely used to treat autoimmune diseases, such as rheumatoid arthritis (RA), ankylosing spondylitis (AS), and nephrotic syndrome (NS) in China [66-70]. TWP is also frequently used for EM treatment in China [71, 72]. A study of retrospective analysis in 40 EM patients with TWP treatment 
TABLE 4: Chinese traditional patent medicine for EM treatment in literatures.

\begin{tabular}{|c|c|c|c|c|c|}
\hline $\begin{array}{l}\text { Chinese traditional } \\
\text { patent medicine; } \\
\text { sample/case number }(n)\end{array}$ & $\begin{array}{c}\text { Control; sample/case } \\
\text { number }(n)\end{array}$ & $\begin{array}{c}\text { Total clinical effect } \\
\text { rate: } \\
\text { total effect rate }(T)^{*} \text {; } \\
\text { dysmenorrhoea } \\
\text { alleviation rate }(D) ; \\
\text { Pregnancy rate }(P)\end{array}$ & $\begin{array}{c}\text { Model } \\
\text { used }\end{array}$ & Therapeutic effects and actions & References \\
\hline $\begin{array}{l}\text { Guizhi Fuling Capsules; } \\
n=40\end{array}$ & $\begin{array}{l}\text { Mifepristone Tablets; } \\
n=40\end{array}$ & $T: 83.3 \%$ verus $87.5 \%$ & $\begin{array}{l}\text { Human } \\
\text { study }\end{array}$ & CA125 $\downarrow$ EMAb $\downarrow$ & {$[102]$} \\
\hline Guizhi Fuling Capsules & & & $\begin{array}{l}\text { SD rat } \\
\text { model }\end{array}$ & $\begin{array}{c}\mathrm{CD}+3 \uparrow \mathrm{CD}+4 \uparrow \\
\mathrm{CD}+4 / \mathrm{CD}+8 \uparrow, \mathrm{CD}+8 \downarrow\end{array}$ & {$[103,104]$} \\
\hline \multirow[t]{2}{*}{$\begin{array}{l}\text { Sanjie Zhentong } \\
\text { Capsules; } n=112\end{array}$} & \multirow[t]{2}{*}{ Danazol; $n=46$} & \multirow[t]{2}{*}{$T: 92.9 \%$ verus $77.5 \%$} & \multirow[t]{2}{*}{$\begin{array}{l}\text { Human } \\
\text { study }\end{array}$} & $\begin{array}{l}\text { Alleviate dysmenorrhoea } \\
\text { Shrink endometrioic lesion }\end{array}$ & {$[105]$} \\
\hline & & & & Recurrence rate $\downarrow$ & {$[106]$} \\
\hline $\begin{array}{l}\text { Yiweikang Granule; } \\
n=50\end{array}$ & Danazol; $n=50$ & $T: 84.0 \%$ verus $86.0 \%$ & $\begin{array}{l}\text { Human } \\
\text { study }\end{array}$ & $\begin{array}{c}\text { CA125 } \downarrow \text { VEGF } \downarrow \text { E2 } \downarrow \\
\text { Alleviate dysmenorrhoea } \\
\text { Shrink endometrioic lesion }\end{array}$ & {$[107,108]$} \\
\hline $\begin{array}{l}\text { Dahuang Zhechong } \\
\text { Wan; } n=26\end{array}$ & Danazol; $n=15$ & $T: 80.8 \%$ verus $86.7 \%$ & $\begin{array}{l}\text { Human } \\
\text { study }\end{array}$ & $\begin{array}{c}\text { EMAb } \downarrow \\
\text { Alleviate dysmenorrhoea } \\
\text { Shrink endometrioic lesion }\end{array}$ & [109] \\
\hline Dahuang Zhechong Wan & Danazol & & $\begin{array}{l}\text { SD rat } \\
\text { model }\end{array}$ & $\mathrm{E} 2 \downarrow \mathrm{PRL} \downarrow \mathrm{P} \uparrow$ & {$[110]$} \\
\hline Xiang Leng Wan; $n=54$ & $\begin{array}{l}\text { Medroxyprogesterone } \\
\text { Acetate Dispersible; } \\
\qquad n=33\end{array}$ & & $\begin{array}{l}\text { Human } \\
\text { study }\end{array}$ & $\begin{array}{c}\text { CA125 } \downarrow \\
\text { Alleviate dysmenorrhoea }\end{array}$ & {$[111]$} \\
\hline Xiang Leng Wan & Danazol & & $\begin{array}{l}\text { SD rat } \\
\text { model }\end{array}$ & IL- $8 \downarrow$ TNF- $\alpha \downarrow$ & {$[112]$} \\
\hline
\end{tabular}

${ }^{*}$ Total effect rate $(T)=$ all effective number of cases/total number of cases; effective case refers to the patients or animal models whose signs and symptoms have been improved after treatment.

from 1986 to 1990 showed that 18 cases were very effective, 17 cases were mildly effective, and 5 cases were ineffective with the therapeutic overall effective rate up to $87.5 \%$ [73]. Another study found that dysmenorrhoea and menstrual disorder of 97.5\% of EM patients with Tripterygium treatment after 3 months were significantly improved and the serum CA125 level was decreased [74]. One research study indicated that the average volume of endometrial implants was significantly reduced, in addition to the endometrial antibody (EMAb) level which was decreased and the changed gonadotropic cells (G-cell) morphology which gradually disappeared in a rabbit EM models treatment with TWP [75].

Curcumin. is a polyphenolic monomer extract from Turmeric, a Chinese herbal medicine which activates microcirculation and possesses various pharmacological activities including anti-inflammatory, antioxidant, and antiproliferative components. In addition, Curcumin may exert beneficial effects on the motor coordination of adolescent rats exposed to ethanol [76]. Both Curcumin and the Chinese medicine formula with Turmeric may significantly alleviate and improve the symptoms of EM patients $[77,78]$. Some studies discovered that the number of microvessels and the protein expression of VEGF were decreased in the ectopic endometrium of rat EM models with Curcumin treatment [79], and the mRNA expression of the tumor necrosis factor- $\alpha$-induced (TNF- $\alpha$-induced) cell surface and total protein expression of intercellular adhesion molecule-1 (ICAM-1) and vascular cell adhesion molecule-1 (VCAM-1) were decreased. Additionally, the secretion of IL-6, IL-8, and monocyte chemotactic protein-1 (MCP-1) was decreased and the activation of transcription factor NF- $\kappa \mathrm{B}$ was suppressed in human endometriotic stromal cells with Curcumin treatment [80]. Some other studies showed that the expression and activities of matrix metalloproteinase (MMP)-2 [81], MMP-3 [82], MMP-9 [83], and VEGF [84] protein were inhibited in rat EM models that received Curcumin treatment, and the endometriotic lesions were reduced.

Puerarin. is a major isoflavonoid compound extracted from Radix puerariae, a Chinese herbal medicine, which has a potential weak estrogenic effect by binding to estrogen receptors (ERs) $[85,86]$. Some studies showed that the weight of endometriotic tissue and the level of serum estrogen were lower in Puerarin and Danazol treatment group than control group at rat EM models [87]; the levels of MMP-9, ICAM-1, and VEGF protein were reduced, while the tissue inhibitor of metalloproteinase-1 (TIMP-1) level was increased in endometriotic stromal cells (ESCs) with Puerarin treatment [86]. The invasion of endometriotic tissue is dependent on MMPs and TIMPs, as they both play a key role in growth and decomposition of endometrium tissue. The VEGF family is the most important in angiogenesis which contributes to 
the growth and invasion of ectopic endometrium. Puerarin may suppress invasion of ESCs and the vascularization of ectopic endometrial tissues by regulation of MMP-9, ICAM1, VEGF, and TIMP-1.

Resveratrol. is a polyphenol which is mainly extracted from grapes, Polygonum cuspidatum, peanuts, mulberry, and other plants. Resveratrol could improve the efficiency of reprogramming mouse embryonic fibroblasts into induced pluripotent stem cells by mimicking hypoxia in cells at a low concentration $(10 \mu \mathrm{mol} / \mathrm{L})$ [88]. Resveratrol has been proposed to treat EM as natural medicine due to its strong antioxidant properties. A research reported that Resveratrol potentiates the effect of oral contraceptives in the alleviation of EMassociated dysmenorrhoea with EM patients by inhibiting aromatase and COX-2 expression in the endometrium [89]. Some studies indicated that the number of endometrial implants decreased by $60 \%$ and the total volume of lesions was reduced by $80 \%$ in rat EM models with Resveratrol treatment [90]; the expression of VEGF was lower in the endometriotic tissue and peritoneal fluid, at the same time, the level of monocyte chemotactic pretein 1 (MCP-1) was also lower in the endometriotic tissue in rat EM models with Resveratrol treatment [91]. Furthermore, Resveratrol inhibited angiogenesis in peritoneal and mesenteric endometriotic lesions by significantly reducing microvessel density and proliferating activity of CD31-positive endothelial cells in the newly developing microvasculature of the lesions in rat EM models treated with Resveratrol for 4 weeks, while at the same time, the growth rate was lower and the final size was smaller within lesions in Resveratrol-treated mice than controls due to lower numbers of proliferating cell nuclear antigen- and Ki67-positive stromal and glandular cells [92].

Green Tea Epigallocatechin-3-Gallate (EGCG). is a catechin monomer extracted from Green tea, the major constituent of which is tea polyphenols. EGCG plays a key role in antioxidation and antiangiogenesis, enhancing apoptosis and inhibiting function of microvessels in the lesions, thereby reducing the size and the weight of lesions and inhibiting the development and growth of experimental EM [93]. What is more, EGCG selectively suppresses the expression of vascular endothelial growth factor C (VEGFC) and tyrosine kinase receptor VEGF receptor 2 (VEGFR2) and reduced VEGFR2 and ERK activation in endothelial cells [94]. Another experiment reported that after treatment with EGCG for 2 weeks, endometriotic lesions and glandular epithelium were smaller or eccentrically distributed by downregulating angiogenic vascular endothelial growth factor A (VEGFA) mRNA levels and upregulating nuclear factor kappa $\mathrm{B}(\mathrm{NF} \kappa \mathrm{B})$ and mitogen activated protein kinase 1 (MAPK-1) mRNA levels in lesions [95]. Furthermore, Laschke et al. found that EGCG could reduce E2-stimulated activation, proliferation, and VEGF expression of endometrial cells in rat EM models, thus preventing the formation of new endometriotic lesions [96].

Ginsenoside Rg3. is found exclusively in the plant genus Panax, a kind of steroid glycosides, and triterpene saponins, which inhibits antioxidative, anti-inflammatory, and matrix metalloproteinase activities. A clinical observation showed that ginsenoside $\mathrm{Rg} 3$ achieved equivalently high efficacy and fewer side effects as compared with gestrinone. Ginsenoside Rg3 could be utilized as clinical medication for EM patients [97]. Furthermore, an experiment observed that the volume of endometriotic lesions was reduced and the microvessel density (MVD) expression was lower in ectopic tissues within ginsenoside $\mathrm{Rg} 3$ treatment group than in the gestrinone group. In addition, ginsenoside Rg3 exhibited an antiangiogenic effect by inhibiting the expression of inhibitors of DNA binding 1 (ID-1) gene and neuropilin-1(NRP1) gene in rat EM models [98-101].

Other Herbal Extracts for Endometriosis Treatment. Herbal extracts are a hot topic in Chinese medicine development with new extracts constantly being investigated; though many reports are not thorough enough to show the mechanism of their treatment for EM. Artemisinin could increase the apoptosis index of the ectopic endometrium by decreased Bcl-2 protein and MVD, thereby significantly decreasing the size of implants in endometriotic rat models as compared to Danazol treatment groups [102]. Querce decreased the size of implants in the rat EM models by reducing the expression of heat shock protein 70 (HSP 70) and VEGF as similar to Danazol treatment group [103].

\subsection{Herbal Patent Medicine Therapies and Mechanisms on} Endometriosis. In the past 10 years, more than 30 herbal patents have been commonly used to treat EM patients in clinic including capsule, pill, and liquid. These patents are made up of several herbs by thousands clinical experiences. Herbal patent is more convenient than the decoction due to modified formulation and is therefore also more suitable for quantitative study. However, the studies about herbal patents in the areas of in-depth mechanism are far less than the herbal decoctions. Some findings about the mechanisms of several commonly used patents were listed as follows.

Some researches indicated that Guizhi Fuling Capsules (GZFLC) was effective for EM treatment. A 3-month clinical observation with $48 \mathrm{EM}$ patients showed that the effective rate was $83.3 \%$ and $87.5 \%$ in GZFLC group and Mifepristone group, respectively. Additionally, the level of serum CA125 was decreased from $(94.45 \pm 23.26) \mathrm{U} / \mathrm{mL}$ and $(96.45 \pm$ $24.13) \mathrm{U} / \mathrm{mL}$ to $(46.47 \pm 11.28) \mathrm{U} / \mathrm{mL}$ and $(43.67 \pm 12.11)$ $\mathrm{U} / \mathrm{mL}$ in GZFLC group and Mifepristone groups, respectiely, while the negative conversion rate of endometrial antibody (EMAb) was $65.0 \%$ and $69.2 \%$, respectively [104]. A study showed that the volume of lesions in rat EM models was reduced from $(331.40 \pm 158.12) \mathrm{mm}^{3}$ to $(50.32 \pm 33.28) \mathrm{mm}^{3}$ after treatment with GZFLC for 4 weeks and the percentage of some immunocytes was significantly increased including $\mathrm{CD}+3, \mathrm{CD}+4, \mathrm{CD}+4 / \mathrm{CD}+8$, and NK cells in rat EM models, indicating that GZFLC plays an important role in suppressing endometriotic implants by regulating the immune function $[105,106]$.

Sanjie Zhentong Capsules (SZC) is commonly used to treat gynecological tumors, including EM. A random singleblind clinical observation showed that the symptoms of $92.9 \%$ and $77.5 \%$ patients were alleviated, respectively, in the SZC 
treatment and the Danazol treatment of 112 EM patients [107]. After laparoscopic surgery, the post-2-year recurrence rates were, respectively, $14.0 \%$ and $13.3 \%$ in SZC treatment group and Danazol treatment group, while being $35.0 \%$ in the control group, indicating that SZC could reduce the post-2year recurrence rate after surgical treatment [108]. However, we have not found any scientific data about the mechanism of SZC in EM animal models.

Other clinical observations indicated that the total effective rate was, respectively, $84 \%$ and $86 \%$ in the Yiweikang Granules (YWKG) treatment group and the Danazol treatment group with $50 \mathrm{EM}$ patients, with the levels of CA125 and VEGF protein in both groups significantly reduced to the same levels after treatment. Furthermore, YWKG could significantly inhibit the growth of ectopic endometrium [109]. Another observation of 100 EM patients showed that YWKG treatment had functions of diminishing ectopic lesion, releasing pelvic pain, improving haemorheology and pelvic blood flow, and the level of serum estradiol (E2) was lowered from $(1458.4 \pm 183.5) \mathrm{pmol} / \mathrm{L}$ to $(1202.0 \pm 153.1)$ $\mathrm{pmol} / \mathrm{L}$ after YWKG treatment [110]. The negative conversion rate of EMAb was $66.7 \%$ with Dahuang Zhechong Wan (DHZCW) and 75\% with Danazol within EM patients. Both DHZCW and Danazol could relieve the clinical symptoms; the total effective rate was $80.8 \%$ and $86.7 \%$, respectively [111]. DHZCW could reduce the levels of serum E2 and prolactin $(\mathrm{PRL})$ and increase the serum progesterone $(\mathrm{P})$ level in rat EM models [112]. Yang found that Xiang Leng Pill (XLP) could reduce the level of serum CA125 from $(93.4 \pm 3.6)$ IU/L to $(48.4 \pm 2.4) \mathrm{IU} / \mathrm{L}$ after 3 -month treatment and relieve symptoms of dysmenorrhoea measured with determination of clinical pain visual analogue scale (VAS) [113]. Another study showed that XLP decreased the levels of interleukin8 (IL 8) and tumor necrosis factor $\alpha$ (TNF- $\alpha$ ) in peritoneal fluid and peripheral blood as did Danazol treatment in rat EM models [114].

\section{Acupuncture and Moxibustion Treatment on Endometriosis}

Acupuncture and Moxibustion treatment is one of the traditional Chinese practices widely used in China and some Asian countries. In China, practitioners of acupuncture and moxibustion regard the human body as a whole based on the theories of meridian, viscera, and Qi-Blood (Chinese medicine believes that $\mathrm{Qi}$ is the most basic form of human material foundation, human life, and activities. Qi and Blood have their different roles but are interdependent with each other, supplying nutrients for the organs and tissues to maintain life activities). Meridian in traditional Chinese medicine (TCM) refers to the pathways of Qi and Blood, and those pathways are interconnected with each other. As a treatment therapy, acupuncture has been used as medical methods since antiquity in China. Currently, it has become an acceptable therapy under strict regulation and has gained a license in 40 states [115]. Gradually, acupuncture has become accepted as a CAM therapy by the United States National Institutes of Health, the National Health Service of the
United Kingdom, and the World Health Organization [116, 117]. As an alternative or complement therapy, Acupuncture and Moxibustion treatment are effective for EM; though a lack of systematic review for these therapies still remains in the scientific literature. This paper will systematically review the utilization and mechanism of Acupuncture and Moxibustion treatment for EM. We found that the acupoint of Ren Meridian (RN) and Spleen Meridian of Foot-Taiyin (SP) is more predominately involved in the Acupuncture and Moxibustion treatment than that of Bladder Meridian (BL) and Kidney Meridian (KI). The main acupoints and minor acupoints for the treatment of EM in Chinese reports are listed in Table 5.

3.1. Acupuncture Treatment on Endometriosis. Acupuncture therapy includes needling, auricular point, and moxamoxibustion. It has the function of dredging meridian, regulating the balance of Yin and Yang (Chinese medicine believes that the balance of Yin and Yang determines people's health), enhancing "Qi-Blood" circulation, thereby strengthening body's resistance to disease and eliminating pathogenic factors. In clinic, acupuncture therapy for EM is confirmed to improve efficacy with fewer side effects, especially in EMassociated dysmenorrhoea. Acupuncture analgesia is usually used to treat pelvic pain and dysmenorrhoea related to EM by mediating the central nervous system (CNS) and releasing some specific neurotransmitters. Zeng and Hong [118] used warm acupuncture (needle warming through moxibustion) and ordinary acupuncture to treat $40 \mathrm{EM}$ patients, respectively, with the same acupoint. Both of these two methods were effective and the effective rate was $95.0 \%$ and $77.5 \%$, respectively. The acupoints used were Guanyuan (RN4), Zhongji (RN3), Tianshu (ST25), Sanyinjiao (SP6), Taichong (LR3), and Zusanli (ST36). Chen and Lin [119] treated a total of 70 patients of EM-related dysmenorrhoea with abdominal acupuncture or Danazol. The acupoints used were Zhongwan (RN12), Xiawan (RN10), Qihai (RN6), Guanyuan (RN4), Zhongji (RN3), and Wailing (ST26), and the treatment was continued for three consecutive menstrual cycles. Results showed that the total effective rate was $91.4 \%$ and $80.0 \%$, respectively. Liu et al. [120] treated $35 \mathrm{EM}$ patients with existing dysmenorrhea with the acupoints of Qihai (RN6), Guanyuan (RN4), Qixue (KI13), Dahe (KI12), Zigong (EXCA1), Diji (SP8), and Taixi (KI3). Results showed that the total effective rate was $77.14 \%$ after treatment for three menstrual cycles. One experiment study showed that both acupuncture and Danazol significantly reduced the level of TNF- $\alpha$ in peritoneal fluid of EM rat model [121].

3.2. Moxibustion Treatment on Endometriosis. Moxibustion originated from the Spring and Autumn Periods and the Warring States Periods in ancient china and has been popular since that time. Moxibustion is a technique which applies heat to acupoints by burning compressed powdered herbal material at the acupoints to stimulate them.

Moxibustion includes moxibustion with moxa cone, moxa stick, and herbal medicine cake, burning rush moxibustion and crude herb moxibustion. Moxibustion with 
TABLE 5: Main acupoints and minor acupoint for the treatment of endometriosis in reports.

\begin{tabular}{|c|c|c|c|c|c|c|c|}
\hline The main acupoint & English name & $N$ & Percentage & The minor acupoint & English name & $N$ & Percentage \\
\hline Guanyuan & RN4 & 46 & $30.67 \%$ & Zusanli & ST36 & 21 & $35 \%$ \\
\hline Sanyinjiao & SP6 & 34 & $22.67 \%$ & Hegu & LI4 & 6 & $10 \%$ \\
\hline Qihai & RN6 & 26 & $17.33 \%$ & Taichong & LR3 & 9 & $15 \%$ \\
\hline Zhongji & RN3 & 17 & $11.33 \%$ & Shenshu & BL23 & 9 & $15 \%$ \\
\hline Zigong & EX-CA1 & 11 & $7.33 \%$ & Wailing & ST26 & 4 & $6.67 \%$ \\
\hline Xuehai & SP10 & 8 & $5.33 \%$ & Tianshu & ST25 & 5 & $8.33 \%$ \\
\hline \multirow[t]{2}{*}{ Diji } & SP8 & 8 & $5.33 \%$ & Taixi & KI3 & 3 & $5 \%$ \\
\hline & & & & Guilai & ST29 & 3 & $5 \%$ \\
\hline
\end{tabular}

Note: $N$ : total number of reports.

moxa cone or moxa stick is most commonly utilized. Chinese medicine believes that the Moxibustion could warm meridians, relieve pain, and promote blood circulation. Chiu [122] analyzes the factors about function of Moxibustion and demonstrates that with the exception of the temperature-related factors, there are some nontemperaturerelated factors, including smoke effects, herbal effects, and biophysical effects (far infrared). She and Xiong [123] treated 20 EM patients of dysmenorrhoea using Guanyuan (RN4), Zhongji (RN3), Qihai (RN6), Tianshu (ST25), Sanyinjiao (SP6), Zigong (EX-CA1), and Ashi points with Ginger Moxibustion. The total effective rate was $95.0 \%$, and following six menstrual cycles, the symptoms of dysmenorrhoea did not recur within 18 patients. Several animal experiments showed that Moxibustion with herbal medicinal cake could treat EM by reducing the levels of serum IL- 6 and plasma PGE2 and increasing the level of plasma 6-keto-PGF1 $\alpha$ [124-126].

\subsection{Acupuncture Combined with Moxibustion Treatment on} Endometriosis. In the clinic, practitioners usually utilize acupuncture and moxibustion together to treat EM. Chen et al. [127] reported that $72 \mathrm{EM}$ patients were treated with acupuncture and moxibustion therapy, 42 patients were pregnant, and the total effective rate was $93.05 \%$. In another observation of 42 cases, EM patients were given techniques of acupuncture combined with moxibustion and results showed that the total curative effective rate was $92.86 \%$ [128]. Combined with acupuncture, moxibustion treatment can effectively arouse the regulating function of meridian, thereby improving the body's immune function to relieve symptoms of EM.

\subsection{Acupoint Injection Treatment on Endometriosis. Acu-} point injection is also known as "water injection" since Chinese herbal and western medicine are injected into acupoints to treat disorders. It is based on the same meridian theory for acupuncture. This therapy collects acupuncture, medicine and meridian effects together. Lin et al. [129] treated rat EM models with acupoint injection. Results showed that acupoint injection with low doses of Alarelin can have an analgesic effect on rat EM models and produce a better effect than intramuscular injection with Alarelin. Sun [130] found that the pelvic mass of ovarian chocolate cysts was significantly reduced in $88.6 \%$ EM patients after treatment by acupoint injection with Chinese herbal mixture, and the acupoints were Sanyinjiao (SP6), Xuehai (SP10), and Zigong (EX-CA1).

3.5. Acupuncture Combined with Chinese Medicine to Treat Endometriosis. In clinic, combining acupuncture and Chinese medicine for EM treatment could achieve better effect through internal recuperate and external stimulation. A study observed 48 patients of EM-associated dysmenorrhoea treated with acupuncture and "Quyu Jiedu Xiaozheng decoction (a kind of Chinese herbal medicine)." The results indicated that the total curative effective rate was 92.0\% [131]. In another clinical observation of $58 \mathrm{EM}$ patients treated with "Shaofu Zhuyu decoction (a kind of Chinese herbal medicine)" combined with acupuncture for three months, results showed that the symptom of dysmenorrhoea among all of the patients disappeared [132]. Zhang [133] treated $53 \mathrm{EM}$ patients by acupuncture and Chinese medicine, the total effective rate was $87.09 \%$, and the pregnancy rate was $40 \%$. The acupoints were Zigong (EX-CA1), Sanyinjiao (SP6), Ligou (LR5), Taichong (LR3), Guanyuan (RN4), and Guilai (ST29). Another clinical observation of EM showed that after treatment with acupuncture and Chinese herbal medicine, the total effective rate was $100 \%$ [134]. Fu and Xia [135] found that after treatment with acupuncture and medicine, the levels of serums CA125, PGE2, and PGF2 $\alpha$ were lower, while the serum $\beta$-EP level was higher than before in EM patients. Chen et al. [136] took the "rat models" acupoint brief as standard to select acupoint [137], treated the EM rat model with acupuncture and Chinese herbal medicine, and found that the volume of the endometriotic implants were reduced and the expression of MMP-2 protein in the ectopic endometrium was increased.

3.6. Electroacupuncture Treatment on Endometriosis. Electroacupuncture (EA) therapy is a new acupuncture therapy that gives the body a bioelectrical trace current after needling into the acupoint. The advantage of EA is that it can control the stimulation for a long time, adjust the physiological functions of the human body, promote blood circulation, adjust muscle tension, and so forth. EA is commonly used to relieve symptoms of pain, arthralgia, and organ dysfunction in clinic. 80 cases of EM patients were randomly divided into ear EA group and body EA group. The symptoms of dysmenorrhoea were significantly relieved, and the plasma 
PGE2 level was decreased, while the plasma 6-Keto-PGF1 $\alpha$ level was increased in both the ear EA and body EA groups [138]. An experiment [139] indicated that EA in the ear acupoints could have an analgesic effect by raising the betaEndorphin $(\beta-\mathrm{EP})$ protein level of the hypothalamus and pituitary in EM rabbit model. Another experiment also found that EA in Guanyuan (RN4) and Diji (SP8) had an analgesic effect on EM rat models by improving the level of $\beta$-EP and Dynorphin protein in the hypothalamus and pituitary of rat EM models [140].

3.7. Acupoint Sticking Treatment on Endometriosis. Acupoint sticking therapy is a noninvasive acupoint therapy via sticking the acupoints with some specially modulated medication, based on the Chinese meridian theory. Acupoint sticking therapy is easy for patients to use themselves, so it is accepted as an adjuvant therapy to the treatment of dysmenorrhoea. There are few research studies about acupoint sticking treatment on EM. The medication typically consists of herbal powder mixed with water, vinegar, wine, egg white, honey, vegetable oil, cool oil, liquid, or saliva. The mechanism of the acupoint sticking therapy is complex and not completely understood yet. Some researchers showed that sticking on acupoint can strengthen drug's absorption and recuperate meridian disorder by directly stimulating acupoint with herbal medicine. An experimental study on EM rat models showed that both sticking with Resina Draconis cataplasma in the Guanyuan (RN4) acupoint and sticking with cataplasma in the same acupoint could inhibit the growth of EM and promote glandular atrophy. It may show its effect by reducing the levels of plasma TXB2 and 6-keto-PGF in rat EM models [141].

3.8. Auricular Acupoint Treatment on Endometriosis. Chinese medicine practitioners believe that acupoint on the ear can reflect the general health of the human body. Certain parts of the human body that are unwell will be apparent within certain auricular areas. Auricular acupoint therapy is applied for the situations of pain, inflammatory diseases, functional disorders, and endocrine and metabolic disorders. In China, auricular acupoint therapy is usually applied as adjuvant therapy with oral decoction or acupuncture and moxibustion therapies. Auricular acupoint therapy can be used as daily care treatment for EM, which is a convenient method to improve the patient's quality of life. Duan et al. [142] found that auricular acupressure could relieve uterine smooth muscle spasm through meridian induction and neurotransmission, reducing the secretion of serum PGE 2.

\section{The Treatment of Chinese Herbal Enema and Microwave Physiotherapy for Endometrioses}

4.1. The Treatment of Chinese Herbal Enema for Endometriosis. Chinese herbal enema is also known as anorectal drug delivery method which consists of pouring Chinese herbal medicine into the rectum where it remains for four to five hours to make the Chinese herbal medicine fully absorb through the intestinal mucosa to treat some specific diseases. This method can reduce the stimulation of the drug to alimentary canal and avoid the damage of the drug by digestive enzymes. Furthermore, Chinese herbal enema can improve the bioavailability of the drug and reduce the damage to the liver and other organs. There were several observations about treatment of EM with Chinese herbal enema which found that Chinese herbal enema has significant therapeutic effect, especially on reducing endometriotic lesions. Zhou [143] treated 64 EM patients with Chinese herbal enema (drugs: Common Burreed Tuber 10 g, Red Peony Root 12 g, Aeruginous Turmeric Rhizome $9 \mathrm{~g}$, Turmeric Root Tuber 10 g, Peach Seed 10 g, Degelatined Deer-horn 12 g, Malaytea Scurfpea Fruit $9 \mathrm{~g}$, Cassia Twig $10 \mathrm{~g}$, Ground Beetle $8 \mathrm{~g}$, inner membrane of chicken gizzard $15 \mathrm{~g}$ ) and found that the total clinical effective rate was $93.8 \%$. Wu [144] treated 51 cases of EM-associated infertility patients who were randomized into two treatment groups with Chinese herbal enema and Danazol treatment for 9 months (drugs: Common Burreed Tuber $10 \mathrm{~g}$, Aeruginous Turmeric Rhizome $10 \mathrm{~g}$, Sargentodoxa cuneata $15 \mathrm{~g}$, Chinese Honeylocust Spine $15 \mathrm{~g}$, Honeycomb $10 \mathrm{~g}$, Red Peony Root $15 \mathrm{~g}$, and Peach Seed $10 \mathrm{~g}$ ). Results showed that the pregnancy rate was $42.4 \%$ and $27.8 \%$, respectively, after followup of 26 months. Zhang and Zhu [145] treated EM patients with retention enema of traditional Chinese herbal medicine (drugs: Danshen Root, Bulb of Thunberg Fritillary, Frankincense, Myrrha, Sargentodoxa cuneata, Patrinia, Cassia bark, Yanhusuo Tuber, Red Peony Root, Chinese Angelica, and Peach Seed) or oral Danazol and the results showed that the effect of both groups was similar, while the adverse reactions were far less in the retention enema group than those of the Danazol group.

4.2. The Treatment of Microwave Physiotherapy on Endometriosis. Microwave is nonionizing radiation and ultrahigh frequency electromagnetic waves with frequency between 300 and $300000 \mathrm{MHz}$ and the wavelength between $1 \mathrm{~mm}$ and $1 \mathrm{~m}$. Before treatment with microwave physiotherapy, the patient's medical history is needed to assess the patient's condition. The microwave physiotherapy should be used only in the nonacute phase of EM; it should be used with caution if the patient has metal implants (such as women with infertility link) in the body. Ask the patients to take supine position and expose the lower abdomen. Put the microwave physiotherapy instrument facing patient's lower abdomen with the distance of $35-45 \mathrm{~cm}$, depending on patient's skin temperature. $30 \mathrm{~min}$ is a course of treatment. Microwave physiotherapy works by absorbing surrounding material and producing a heating effect, without changing the chemical nature of the surrounding substance, and has high security [146]. Kanaoka Y found that microwave physiotherapy could adjust menorrhagia and inhibit uterus enlargement caused by adenomyosis [147]. As an adjuvant treatment for EM, microwave physiotherapy shows a synergistic effect which increases the absorption rate of Chinese herbal medicine.

4.3. Chinese Herbal Enema Combined with Microwave Physiotherapy for the Treatment of Endometriosis. Chinese herbal 
enema and microwave physiotherapy are always combined for the treatment of endometrioses as adjuvant therapy which can produce a heating effect to promote increased absorption of Chinese herbal enema via rectum mucosa. Chinese herbs formula used as enemas can be modified according to the various symptoms patients present with. Microwave treatment is utilized after Chinese herbal retention enema to strengthen the permeation of medication and promote the absorption and metabolism of inflammation and exudates. Since the rectum and pelvic organs are close to each other, herbal enema can be directly absorbed through the rectum and affect the lesion site directly [148]. Some clinical studies showed that Chinese herbal enemas combined with microwave physiotherapy could effectively relieve the symptoms of lower abdominal pain, shrink cysts, and increase the conception rate; the total effective rate was $94.2 \%$, the pregnancy rate was $45 \%$, and the symptoms of dysmenorrhoea and menstrual disorder almost decreased entirely [149-151].

4.4. Chinese Herbal Enema Combined with Oral Chinese Medicine on Treatment of Endometriosis. Chinese herbal enemas combined with oral Chinese herbal medicine are the most commonly utilized treatment for EM patients who are treated in hospital, with the total effective rate varying between $83.8 \%$ and $93.88 \%$ [152-156].

\section{Others CAM Therapies}

There are some other therapies effective for EM in addition to these therapies mentioned above, such as hypnosis [157] and thermal biofeedback [158]. While there is lack of detailed data about the mechanisms, we will continue to focus on future avenues of research in this field.

\section{Conclusions}

CAM therapies utilized in patients with EM in the literature include herbs, acupuncture, CHM enema, microwave physiotherapy, and psychological intervention. None of these therapies are entirely curative for EM and neither can they fully eradicate the endometriotic lesions. These therapies may effectively modulate the progress of EM, however, by shrinking the lesions, suppressing the symptoms, and decreasing the recurrence rate. Although, CAM therapies have been gradually accepted in some countries, some obstacles-such as the lack of more thorough safety and efficacy studiesstill hinder more widespread application of CAM therapies throughout the world. We found some mainly additional obstacles including: (1) selective publication of only positive results with varying study qualities and standards, (2) lack of large-sample sizes and randomized controlled trials, (3) and the lack of confirmatory animal studies with therapies such as auricular acupoint, Chinese herbal enema, microwave physiotherapy, and psychological intervention. The molecular mechanisms of some CAM therapies need to be further investigated and confirmed in the future.
In summary, the active principle of the CAM therapies has a strong scientific foundation and researchers are increasing their interest in this area of medical treatment. Standardizations of the effective CAM therapies are still needed, however, including managing the pharmaceutical form of herbal agents and controlling the quality of acupuncture methods in order to increase the benefits of these alternative medical interventions to patients with EM throughout the world.

\section{Authors' Contribution}

Sai Kong and Yuehui Zhang contributed equally to this work and should be considered cofirst authors.

\section{Conflict of Interests}

The authors declare that there is no conflict of interests regarding the publication of this paper.

\section{Acknowledgments}

This paper is supported by the National Natural Science Fund of China (Grant no. 81273788); the Program for New Century Excellent Talents in Heilongjiang Provincial University (Grant no. 1155-NCET-015).

\section{References}

[1] L. C. Giudice and L. C. Kao, "Endometriosis," The Lancet, vol. 364, no. 9447, pp. 1789-1799, 2004.

[2] R. E. Batt, A History of Endometriosis, Springer, London, UK, 2011.

[3] B. C. J. M. Fauser, K. Diedrich, P. Bouchard et al., "Contemporary genetic technologies and female reproduction," Human Reproduction Update, vol. 17, no. 6, pp. 829-847, 2011.

[4] N. Sinaii, S. D. Cleary, M. L. Ballweg, L. K. Nieman, and P. Stratton, "High rates of autoimmune and endocrine disorders, fibromyalgia, chronic fatigue syndrome and atopic diseases among women with endometriosis: a survey analysis," Human Reproduction, vol. 17, no. 10, pp. 2715-2724, 2002.

[5] C. Wellbery, "Diagnosis and treatment of endometriosis," American Family Physician, vol. 60, no. 6, pp. 1753-1762, 1999.

[6] S.-W. Guo, P. Simsa, C. M. Kyama et al., "Reassessing the evidence for the link between dioxin and endometriosis: from molecular biology to clinical epidemiology," Molecular Human Reproduction, vol. 15, no. 10, pp. 609-624, 2009.

[7] B. Ruhland, A. Agic, J. Krampe, K. Diedrich, and D. Hornung, "Innovations in conservative endometriosis treatment: an updated review," Minerva Ginecologica, vol. 63, no. 3, pp. 247249, 2011.

[8] Recurrent Endometriosis: Surgical Management, Endometriosis, The Cleveland Clinic, 2010.

[9] National Center for Complementary and Alternative Medicine, http://nccam.nih.gov.

[10] I. Loudon, "A brief history of homeopathy," Journal of the Royal Society of Medicine, vol. 99, no. 12, pp. 607-610, 2006.

[11] I. D. Coulter and E. M. Willis, "The rise and rise of complementary and alternative medicine: a sociological perspective," Medical Journal of Australia, vol. 180, no. 11, pp. 587-589, 2004. 
[12] L. A. M. Pujol and D. A. Monti, "Managing cancer pain with nonpharmacologic and complementary therapies," The Journal of the American Osteopathic Association, vol. 107, no. 12, pp. ES15-ES21, 2007.

[13] P. M. Barnes, E. Powell-Griner, K. McFann, and R. L. Nahin, "Complementary and alternative medicine use among adults: United States, 2002," Advance data, no. 343, pp. 1-19, 2004.

[14] A. Kellehear, "Complementary medicine: is it more acceptable in palliative care practice?" Medical Journal of Australia, vol. 179, no. 6, pp. S46-S48, 2003.

[15] D. Z. Wang, Z. Q. Wang, and Z. F. Zhang, "Treatment of endometriosis with removing blood stasis and purgation method," Chinese Journal of Integrated Traditional and Western Medicine, vol. 11, no. 9, pp. 524-526, 1991.

[16] D. Wang, Z. Wang, and C. Yu, "Endometriosis treated by the method of resolving blood stasis to eliminate obstruction in the lower-jiao," Journal of Traditional Chinese Medicine, vol. 18, no. 1, pp. 7-11, 1998.

[17] J. Li, J. Zheng, and D. Wang, "Clinical observation on treatment of endometriosis by tonifying qi and promoting blood circulation to remove stasis and purgation principle," Chinese Journal of Integrated Traditional and Western Medicine, vol. 19, no. 9, pp. 533-535, 1999.

[18] Z. Zhang, C. Hu, W. Tang et al., "Therapeutic potential of Wenshen Xiaozheng Tang: a traditional chinese medicine prescription for treating endometriosis," Reproductive Sciences, vol. 20, no. 10, pp. 1215-1223, 2013.

[19] A. Flower, G. T. Lewith, and P. Little, "Seeking an oracle: using the Delphi process to develop practice guidelines for the treatment of endometriosis with Chinese herbal medicine," Journal of Alternative and Complementary Medicine, vol. 13, no. 9, pp. 969-976, 2007.

[20] Q. Wang, H. Zhao, Q. Xiang et al., "Effect of Yikun Neiyi Wan on the expression of aromatase P450, COX-2, and ER related receptor in endometrial cells in vitro from patients with endometriosis," Journal of Traditional Chinese Medicine, vol. 29, no. 4, pp. 296-300, 2009.

[21] M. Chen, H. Zhang, J. Li, and G.-R. Dong, "Clinical observation on acupuncture combined with acupoint sticking therapy for treatment of dysmenorrhea caused by endometriosis," Chinese Acupuncture \& Moxibustion, vol. 30, no. 9, pp. 725-728, 2010.

[22] D.-F. Xiang, Q.-Z. Sun, and X.-F. Liang, "Effect of abdominal acupuncture on pain of pelvic cavity in patients with endometriosis," Chinese Acupuncture \& Moxibustion, vol. 31, no. 2, pp. 113-116, 2011.

[23] M. Z. Ma, "Xuefu Zhuyu Decoction for treatment of 83 endometriosis patients," Shanghai Journal of Traditional Chinese Medicine, vol. 2, pp. 16-17, 1993.

[24] S. Y. Zhang and Y. Y. Wang, "Xuefu Zhuyu Decoction for treatment of 36 endometriosis patients," Chinese Journal of Ethnomedicine and Ethnopharmacy, vol. 22, p. 84, 2011.

[25] J. Y. Zhang, "Clinical observation of 79 endometriosis patients treated with Xuefu Zhuyu Decoction," Zhejiang Journal of Traditional Chinese Medicine, vol. 43, no. 8, p. 455, 2008.

[26] C. F. Wang, "Clinical observation of 60 endometriosisassociated dysmenorrhoea patients treated with Xuefu Zhuyu Decoction," Modern Journal of Integrated Traditional Chinese and Western Medicine, vol. 16, no. 14, pp. 1931-1932, 2007.

[27] A. Z. Gao, "Xuefu Zhuyu Decoction for treatment of 42 endometriosis patients," Guangming Journal of Chinese Medicine, vol. 27, no. 4, pp. 717-718, 2012.
[28] D. L. Fang, "Clinical observation of endometriosis patients treated with Xuefu Zhuyu Decoction," Clinical Journal of Anhui Traditional Chinese Medicine, vol. 15, no. 4, pp. 297-298, 2003.

[29] L. Pan and H. Zheng, "Effect of xiaochaihu soup on the expression of COX-2 and P450arom of endometriosis in rats," Journal of Medical Research, vol. 40, no. 8, pp. 126-128, 2011.

[30] Z. M. Altan, D. Denis, D. Kagan, E. M. Grund, S. S. Palmer, and S. G. Nataraja, "A long-acting tumor necrosis factor $\alpha$ binding protein demonstrates activity in both in vitro and in vivo models of endometriosis," Journal of Pharmacology and Experimental Therapeutics, vol. 334, no. 2, pp. 460-466, 2010.

[31] K. L. Sharpe-Timms, H. Nabli, R. L. Zimmer, J. A. Birt, and J. W. Davis, "Inflammatory cytokines differentially up-regulate human endometrial haptoglobin production in women with endometriosis," Human Reproduction, vol. 25, no. 5, pp. 12411250, 2010.

[32] B. Scholl, N. A. Bersinger, A. Kuhn, and M. D. Mueller, "Correlation between symptoms of pain and peritoneal fluid inflammatory cytokine concentrations in endometriosis," Gynecological Endocrinology, vol. 25, no. 11, pp. 701-706, 2009.

[33] W. J. Zhang, Z. N. Wang, P. E. Zhen, and H. Zheng, "The regulation of Xiaochaihu Decoction on interleukin-8 and tumor necrosis factor in endometriotic tissues," Shaanxi Journal of Traditional Chinese Medicine, vol. 5, pp. 468-470, 2004.

[34] Z. N. Wang, W. J. Zhang, H. Zheng et al., "Effects of Xiaochaihutang, a Chinese medicine, and danazol on angiogenesis in rat endometriosis model," Chinese Journal of Pathophysiology, vol. 20, no. 5, pp. 862-865, 2004.

[35] H. Zheng and L.-D. Zuo, "Experimental study on treatment of endometriosis with xiaochaihu decoction," Chinese Journal of Integrated Traditional and Western Medicine, vol. 26, supplement 1, pp. 119-122, 2006.

[36] H. Zheng, H. Y. Li, and L. D. Zuo, "An experimental study of mechanism in treatment for endometriosis with Xiao Chai $\mathrm{Hu}$ Tang in rats," Labeled Immunoassays and Clinical Medicine, vol. 12, no. 1, pp. 35-37, 2005.

[37] H. Zheng and L. D. Zuo, "Experimental study of the treatment of Xiaochaihu Tang on endometriosis rats," Shaanxi Journal of Traditional Chinese Medicine, vol. 26, no. 9, pp. 1147-1149, 2006.

[38] J. B. Yang and F. J. Piao, "Clinical study of the treatment of Quyikang on 30 endometriosis patients," Yunnan Journal of Traditional Chinese Medicine and Materia Medica, vol. 27, no. 5, pp. 32-34, 2006.

[39] J. B. Yang, Q. R. Meng, M. Chen et al., "Effect of quyikang on VEGF of endometriosis in rats," Chinese Archives of Traditional Chinese Medicine, vol. 26, no. 5, pp. 979-981, 2008.

[40] D. Wickiewicz, A. Chrobak, G. B. Gmyrek et al., "Diagnostic accuracy of interleukin-6 levels in peritoneal fluid for detection of endometriosis," Archives of Gynecology and Obstetrics, vol. 288, no. 4, pp. 805-814, 2013.

[41] J. B. Yang and C. Xu, "Effects of Quyikang on IL-2 and IL6 in peritoneal fluid of endometriosis rats," Yunnan Journal of Traditional Chinese Medicine and Materia Medica, vol. 28, no. 10, pp. 36-39, 2007.

[42] J. B. Yang and N. Li, "QuYi Kang: its effects on ER and $\beta$ EP in rats with endometriosis," Journal of Shaanxi College of Traditional Chinese Medicine, vol. 31, no. 1, pp. 46-50, 2008.

[43] J. B. Yang and Y. L. Du, "Qu Yi Kang: its effects on hemorheology of rats with endometriosis," Modern Traditional Chinese Medicine, vol. 29, no. 1, pp. 48-49, 2009. 
[44] F. Yang, Y. Wang, S. M. Yang, and J. B. Yang, "Qu Yi Kang: its effects on TXB2 and 6-Keto-PGF1 $\alpha$ in rats with endometriosis," Shaanxi Journal of Traditional Chinese Medicin, vol. 32, no. 11, pp. 1557-1558, 2011.

[45] X. Y. Xu, H. F. Consg, and B. Z. Ma, "Clinical observation on 46 endometriosis patients treated with Yiweining," Medical Information, vol. 24, pp. 3172-3173, 2011.

[46] W. G. Ma, X. Y. Xu, W. H. Tan, B. Z. Ma et al., "Empirical study of effect of YiWeiNing on expression of Fas/FasL in rat with endometriosis," Chinese Journal of Traditional Chinese Medicine and Pharmacy, vol. 22, no. 12, pp. 879-881, 2007.

[47] F. Qu, W. G. Ma, D. X. Yang, and B. Z. Ma, "The effect of YiWeiNing on the expression of relevant apoptosis gene in the rats with endometriosis," Journal of Sichuan of Traditional Chinese Medicine, vol. 12, no. 24, pp. 9-10, 2006.

[48] X. Y. Xu, H. F. Cong, W. G. Ma, and B. Z. Ma, "Effects of YiWeiNing recipe on expressions of cyclo-oxygenase-2mRNA in ectopic endometrium of rats with endometriosis," Journal of Sichuan of Traditional Chinese Medicine, vol. 29, no. 7, pp. 28-30, 2011.

[49] H. Koike, H. Egawa, T. Ohtsuka, M. Yamaguchi, T. Ikenoue, and N. Mori, "Correlation between dysmenorrheic severity and prostaglandin production in women with endometriosis," Prostaglandins Leukotrienes and Essential Fatty Acids, vol. 46, no. 2, pp. 133-137, 1992.

[50] H. Koike, T. Ikenoue, and N. Mori, "Studies on prostaglandin production relating to the mechanism of dysmenorrhea in endometriosis," Nippon Naibunpi Gakkai zasshi, vol. 70, no. 1, pp. 43-56, 1994.

[51] F. Wu, H. Z. Zhang, J. C. Hu et al., "The affections of yiwei powder on uterine contraction and vasoactive substance of the rabbits with experimental endometriosis," Chinese Journal of Information on Traditional Chinese Medicine, vol. 10, no. 9, pp. 29-30, 2003.

[52] F. Wu, F. Chen, and Y. P. Kang, "Effects of Yiweisan on hemorheology and vasoactive substances in Rabbit with Endometriosis," Journal of Chinese Microcirculation, vol. 7, no. 6, pp. 355-356, 2003.

[53] M. Pino, C. Galleguillos, M. Torres et al., "Association between MMP1 and MMP9 activities and ICAM1 cleavage induced by tumor necrosis factor in stromal cell cultures from eutopic endometria of women with endometriosis," Reproduction, vol. 138, no. 5, pp. 837-847, 2009.

[54] R. H. Zhao, Y. H. Yang, M. Li, C. Xu, and W. Y. Xia, "Influences of Huoxue Xiaoyi Fang on ICAM-1, MMP- and VEGF in rats with endometriosis," Journal of Beijing University OfTraditional Chinese Medicine, vol. 35, no. 12, pp. 826-899, 2012.

[55] Y. H. Yang, R. H. Zhao, and C. Xu, "Effect of the herbal medicine of Huoxue Xiaoyi decoction on the rat model of recurrence of endometriosis," China Journal of Traditional Chinese Medicine and Pharmacy, vol. 27, no. 7, pp. 1911-1913, 2012.

[56] J. R. Fu, J. Zhen, F. Wang, H. Y. Xu, and L. X. Tian, "Effects of neiyifang on IL-2 and TNF- $\alpha$ in serum and peritoneal fluid of endometriosis rats," China Journal of Traditional Chinese Medicine and Pharmacy, vol. 30, no. 3, pp. 537-539, 2012.

[57] J. H. Chen and L. J. Chen, "Effects of Neiyi Zhitong decoction on endometrium histomorphology of endometriosis rats," Modern Medicine Journal of China, vol. 8, no. 9, pp. 20-22, 2006.

[58] L. J. Chen, J. H. Chen, D. D. Zhang et al., "Effects of Neiyi Zhitong decoction on serum CA125, PGF2 $\alpha$ and PGE2 of endometriosis rats," Acta Chinese Medicine and Pharmacology, vol. 32 , no. 6 , pp. 39-41, 2004.
[59] P. H. Zhang and J. F. Liu, "Clinical observation of endometriosis patients treated with Fuzheng Huayu decoction," Journal of New Chinese Medicine, vol. 44, no. 6, pp. 60-61, 2012.

[60] S. H. Shi, D. G. Li, and X. X. Meng, "Effect of Huazhuo Jiedu Huoxue recipe on plasma orphanin FQ and prostaglandins in the patients of endometriosis with pain," Chinese Traditional Patent Medicine, vol. 29, no. 6, pp. 788-790, 2007.

[61] J. Y. Luo, M. L. Cheng, M. L. Chen et al., "Clinical study on endometriosis patients treated with Yi Kun Decoction," Modern Journal of Integrated Traditional Chinese and Western Medicine, vol. 15, no. 12, pp. 1626-1627, 2006.

[62] Y. M. Lin, L. Li, and G. F. Pang, "Effect of level of IL-6 in ascitic fluid to white rabbit of juantongyin in treating endometriosis," Journal of Liaoning University of Traditional Chinese Medicine, vol. 14, no. 2, pp. 73-75, 2012.

[63] B. J. Fu, S. Y. Sun, and T. T. Ding, "Clinical study on Xianji Pill in treating 70 cases of dysmenorrhea in adenomyosis of blood and heat accumulation," Shanghai Journal of Traditional Chinese Medicine, vol. 42, no. 8, pp. 53-54, 2008.

[64] Z. Z. Zhang, C. P. Hu, W. W. Tang et al., "Wenshen Xiaozheng Tang suppresses the growth of endometriosis with an antiangiogenic effect," Climacteric, vol. 16, no. 6, pp. 700-708, 2013.

[65] Z. Zhang, C. Hu, W. Tang et al., "Therapeutic potential of Wenshen Xiaozheng Tang, a traditional Chinese medicine prescription, for treating endometriosis," Reproductive Sciences, vol. 20, no. 10, pp. 1215-1223, 2013.

[66] R. X. Bai, “Tripterygium tincture treatment of rheumatoid arthritis and ankylosing spondylitis: a double-blind clinical observation," Chinese Journal of Orthopaedics, vol. 18, no. 4, p. 290, 1988.

[67] Y. Wang and Y. M. Lin, "Treatment of rheumatoid arthritis with Tripterygium Wilfordii polyglycoside: a clinical observation of 32 Cases," Strait Pharmaceutical Journal, vol. 9, no. 3, pp. 101102, 1997.

[68] Z. X. Li and H. Tan, "The clinical efficacy of myasthenia gravis treated with Tripterygium wilfordii and effect on IL-6," Chinese Journal of Integrated Traditional and Western Medicine, vol. 22, no. 3, p. 294, 2002.

[69] C. R. Dou and J. H. Bai, "Clinical observation of rheumatoid arthritis treated with Tripterygium wilfordii," Journal of Gansu College of Traditional Chinese Medicine, vol. 15, no. 2, p. 25, 1998.

[70] X. H. Yan, X. M. Zhang, and Z. H. Qiu, "Clinical research of Tripterygium apozem treatment for IgA nephropathy with albuminuria," Fujian Journal of Traditional Chinese Medicine, vol. 35, no. 3, pp. 11-12, 2004.

[71] W. J. Yang and J. Q. Zhang, "Treatment of endometriosis with tripterygium wilfordii polyglycoside tablets: a clinical observation of 120 cases," Jiangsu Journal of Traditional Chinese Medicine, vol. 18, no. 9, p. 22, 1997.

[72] D. F. Chen, "Treatment of endometriosis with tripterygium: a clinical observation," Chinese Journal of Integrated Traditional and Western Medicine, vol. 23, no. 3, p. 170, 2003.

[73] D. F. Chen, Y. F. Wu, and W. Di, “Treatment of endometriosis with tripterygium," Shanghai Journal of Traditional Chinese Medicine, vol. 28, no. 9, pp. 6-9, 1994.

[74] J. H. Gu, J. L. He, and M. D. Wang, "Treatment of endometriosis with tripterygium: a clinical observation of 40 cases," Journal of Traditional Chinese Medicine, vol. 10, no. 5, pp. 301-303, 2003.

[75] Y. H. Xiao, D. P. Chen, J. H. Yan, and Y. Yokoyama, "Mechanism of action of Tripterygium Wilfordii polyglycoside on experimental endometriosis," European Journal of Gynaecological Oncology, vol. 23, no. 1, pp. 63-67, 2002. 
[76] G. Partadiredja, Sutarman, T. N. Yahya, C. T. Nuryana, and R. Susilowati, "Curcumin alters motor coordination but not total number of Purkinje cells in the cerebellum of adolescent male Wistar rats," Journal of Integrative Medicine, vol. 11, no. 1, pp. 3238, 2013.

[77] R. Chen, H. Liu, R. JiangG, X. Li, and Y. F. Qu, "Effect of traditional Chinese medicine (Daqiqi Tang) on expresstions of VEGF and MMP-9 in endometriosis rats," Reproduction \& Contraception, vol. 30, no. 10, pp. 659-663, 2010.

[78] Q. S. Hang, Y. Fang, L. Wang, and R. Chen, "Effect of Da Qiqi decoction on expression of P450 and COX-2 in endometriosis of rats," Journal of Third Military Medical University, vol. 34, no. 21, pp. 2167-2171, 2012.

[79] Y. Zhang, H. Cao, Y.-Y. Hu, H. Wang, and C.-J. Zhang, "Inhibitory effect of curcumin on angiogenesis in ectopic endometrium of rats with experimental endometriosis," International Journal of Molecular Medicine, vol. 27, no. 1, pp. 87-94, 2011.

[80] K.-H. Kim, E. N. Lee, J. K. Park et al., "Curcumin attenuates TNF- $\alpha$-induced expression of intercellular adhesion molecule1, vascular cell adhesion molecule-1 and proinflammatory cytokines in human endometriotic stromal cells," Phytotherapy Research, vol. 26, no. 7, pp. 1037-1047, 2012.

[81] S. Jana, D. S. Rudra, S. Paul, and S. Snehasikta, "Curcumin delays endometriosis development by inhibiting MMP-2 activity," Indian Journal of Biochemistry \& Biophysics, vol. 49, no. 5, pp. 342-348, 2012.

[82] S. Jana, S. Paul, and S. Swarnakar, "Curcumin as antiendometriotic agent: implication of MMP-3 and intrinsic apoptotic pathway," Biochemical Pharmacology, vol. 83, no. 6, pp. 797-804, 2012.

[83] S. Swarnakar and S. Paul, "Curcumin arrests endometriosis by downregulation of matrix metalloproteinase-9 activity," Indian Journal of Biochemistry and Biophysics, vol. 46, no. 1, pp. 59-65, 2009.

[84] R. Chen, J. L. Chen, and Y. Fang, "Effect of curcuma on expressions in endometriosis rats," Chinese Traditional Patent Medicine, vol. 33, no. 7, pp. 1145-1148, 2011.

[85] W. Cheng, L. Z. Chen, and S. S. Yang, "Puerarin suppresses proliferation of endometriotic stromal cells partly via the MAPK signaling pathway induced by $17 \beta$-estradiol-BSA," PLoS ONE, vol. 7, no. 9, Article ID e45529, 2012.

[86] D. Wang, Y. Liu, J. Han et al., "Puerarin suppresses invasion and vascularization of endometriosis tissue stimulated by $17 \beta$ estradiol," PLoS ONE, vol. 6, no. 9, Article ID e25011, 2011.

[87] Y. Chen, C. Chen, S. Shi et al., "Endometriotic implants regress in rat models treated with puerarin by decreasing estradiol level," Reproductive Sciences, vol. 18, no. 9, pp. 886-891, 2011.

[88] D. F. Ding, X. F. Li, H. Xu et al., "Mechanism of resveratrol on the promotion of induced pluripotent stem cells," Journal of Integrative Medicine, vol. 11, no. 6, pp. 389-396, 2013.

[89] H. Maia Jr, C. Haddad, N. Pinheiro, and J. Casoy, "Advantages of the association of resveratrol with oral contraceptives for management of endometriosis-related pain," International Journal of Women's Health, vol. 4, pp. 543-549, 2012.

[90] K. L. Bruner-Tran, K. G. Osteen, H. S. Taylor, A. Sokalska, K. Haines, and A. J. Duleba, "Resveratrol inhibits development of experimental endometriosis in vivo and reduces endometrial stromal cell invasiveness in vitro," Biology of Reproduction, vol. 84, no. 1, pp. 106-112, 2011.

[91] A. M. Ergenoglu, A. O. Yeniel, O. Erbas et al., "Regression of endometrial implants by resveratrol in an experimentally induced endometriosis model in Rats," Reproductive Sciences, vol. 20, no. 10, pp. 1230-1236, 2013.

[92] J. Rudzitis-Auth, M. D. Menger, and M. W. Laschke, "Resveratrol is a potent inhibitor of vascularization and cell proliferation in experimental endometriosis," Human Reproduction, vol. 28, no. 5, pp. 1339-1347, 2013.

[93] C. C. Wang, H. Xu, G. C. Man et al., "Prodrug of green tea epigallocatechin-3-gallate (Pro-EGCG) as a potent antiangiogenesis agent for endometriosis in mice," Angiogenesis, vol. 16, no. 1, pp. 59-69, 2013.

[94] H. Xu, C. M. Becker, W. T. Lui et al., "Green tea epigallocatechin3-gallate inhibits angiogenesis and suppresses vascular endothelial growth factor C/vascular endothelial growth factor receptor 2 expression and signaling in experimental endometriosis in vivo," Fertility and Sterility, vol. 96, no. 4, pp. 1021-1028, 2011.

[95] H. Xu, W. T. Lui, C. Y. Chu, P. S. Ng, C. C. Wang, and M. S. Rogers, "Anti-angiogenic effects of green tea catechin on an experimental endometriosis mouse model," Human Reproduction, vol. 24, no. 3, pp. 608-618, 2009.

[96] M. W. Laschke, C. Schwender, C. Scheuer, B. Vollmar, and M. D. Menger, "Epigallocatechin-3-gallate inhibits estrogen-induced activation of endometrial cells in vitro and causes regression of endometriotic lesions in vivo," Human Reproduction, vol. 23, no. 10, pp. 2308-2318, 2008.

[97] J. R. Long and Z. Li, "Ginsenoside Rg3 in combination with surgery in patients with stage III-IV endometriosis: a clinical control trial," Chinese Remedies \& Clinics, vol. 12, no. 6, pp. 720 $724,2012$.

[98] Z. Y. Song, Z. Li, M. C. Zhi, and Y. H. Jiang, "The observation of inhibition effect of Ginsenoside Rg3 on endometriosis rats model," Chinese Remedies \& Clinics, vol. 6, no. 4, pp. 255-256, 2006.

[99] Z. Li, M. C. Zhi, X. L. Li et al., "Control study of Ginsenosides and Gestrinone on the treatment of endometriosis rats," Chinese Journal of Obstetrics and Gynecology, vol. 42, no. 6, pp. 417-418, 2007.

[100] Z. Y. Song, K. Fu, L. Y. Hu et al., “The inflnence of ginsenoside Rg3 on ID-1 and NRP-1 gene expression in endometriotic tissues," Chinese Remedies \& Clinics, vol. 11, no. 7, pp. 768-772, 2011.

[101] L. J. Du, Y. H. Yao, K. Fu et al., "Effect of Ginsenoside Rg3 on expression of ID-1 gene in the endometriosis tissue," Chinese Remedies \& Clinics, vol. 10, no. 6, pp. 655-656, 2010.

[102] X. Wang, J. Fang, H. J. Wang et al., "The efficacy of Artemisinin on treatment of endometriosis rats," Guangdong Medical Journal, vol. 32, no. 2, pp. 163-167, 2011.

[103] X. Zhang, X. Wang, H.-J. Wang, Q. Yang, and M.-R. Qie, "Inhibition effect and mechanisms of quercetin on surgically induced endometriosis," Journal of Sichuan University, vol. 40, no. 2, pp. 228-244, 2009.

[104] Y. L. Liu, J. L. Wang, D. M. Xiao et al., "Treatment of endometriosis with guizhi fuling capsule: a clinical observation of 48 cases," Shandong Medical Journal, vol. 50, no. 39, pp. 78-79, 2010.

[105] X. Ji, J. Gao, X. Cai et al., "Immunological regulation of Chinese herb Guizhi Fuling Capsule on rat endometriosis model," Journal of Ethnopharmacology, vol. 134, no. 3, pp. 624-629, 2011.

[106] H. Z. Liu, F. Y. Qiao, S. H. Chen et al., "Effects of guizhifuling extracture on immune function in experimental rats with endometriosis," Herald of Medicine, vol. 17, pp. 566-568, 2005. 
[107] Z. H. Huang, "The clinical application of Sanjie Zhentong capsules after laparoscopic surgery in the pelvic endometriosis," Chinese Journal of Integrated Traditional and Western Medicine, vol. 8, p. 748, 2007.

[108] Y. L. Ren, S. H. Hu, and H. J. Zhang, "Treatment efficacy and follow-up survey on 112 endometriosis patients treated with Sanjie Zhentong capsule," Journal of Chinese Practical Diagnosis and Therapy, vol. 19, no. 4, p. 279, 2005.

[109] H. Q. Zhang, D. H. Ma, J. M. Song et al., "Clinical observation on 50 endometriosis cases treated with Yiweikang Granules," Journal of Traditional Chinese Medicine, vol. 52, no. 1, pp. 2730, 2011.

[110] H. Q. Zhang, S. P. Zhao, Y. J. Liu et al., "Clinical and experimental study on Yiweikang for endometriosis," Modern Medicine Journal of China, vol. 11, no. 7, pp. 13-18, 2009.

[111] L. Cheng and X. B. Li, "Clinical observation of Dahuang Zhechong Wan on the treatment of endometriosis," Guangdong Medical Journal, vol. 20, no. 7, pp. 565-566, 1999.

[112] F. Zhao, Y. Li, H. L. Ding et al., "Effects of Dahuang Zhechong Wan on the sex-hormone endometriosis rats," Traditional Chinese Medicine Research, vol. 21, no. 9, pp. 14-16, 2008.

[113] C. B. Yang, Y. Chen, H. M. Jin et al., "Effects of Xiang Leng Wan on dysmenorrhea and serum CA125 of patients with endometriosis," China Journal of Chinese Materia Medica, vol. 33, no. 5, pp. 567-569, 2008.

[114] Y. J. Tang, Y. Chen, and H. Y. Yu, "Effects of Xiangleng pill on cytokine in endometriosis model rat," China Journal of Chinese Materia Medica, vol. 30, no. 14, pp. 1108-1110, 2005.

[115] National Certification Commission for Acupuncture and Oriental Medicine, http://www.nccaom.org/.

[116] NIH Consensus Development Program, "Acupunctureconsensus development conference statement," National Institutes of Health, July 2007.

[117] US National Center for Complementary and Alternative Medicine, "Acupuncture," Original, 2006.

[118] R. Zeng and W. Hong, "Clinical study of 40 cases with warm acupuncture treating endometriosis," China Journal of Chinese Medicine, vol. 25, no. 147, pp. 342-343, 2010.

[119] L. N. Chen and Y. Lin, "The treatment of 70 endometriosis patients of dysmenorrhoea with abdominal acupuncture," Shandong Journal of Traditional Chinese Medicine, vol. 30, no. 6, pp. 403-405, 2011.

[120] Y. Y. Liu, Y. Ai, Y. F. Xi et al., "Efficacy of different methods of acupuncture in the treatment of endometriosis-associated dysmenorrhoea," Hubei Journal of Traditional Chinese Medicine, vol. 3, no. 7, pp. 53-54, 2009.

[121] G. M. Huo, S. P. Li, S. Zhou et al., "Experimental study of the acupuncture intervention role on peritoneal fluid TNFalpha of endometriosis rat," Hubei Journal of Traditional Chinese Medicine, vol. 28, no. 7, pp. 8-9, 2006.

[122] J.-H. Chiu, "How does moxibustion possibly work?" EvidenceBased Complementary and Alternative Medicine, vol. 2013, Article ID 198584, 8 pages, 2013.

[123] C. She and J. Xiong, "Acupuncture treatment on 20 endometriosis patients," Shanghai Journal of Acupuncture and Moxibustion, vol. 31, no. 3, pp. 178-179, 2012.

[124] H. M. Wang and S. Y. Feng, "Study of Cake-separated moxibustion on serum IL-6 levels in endometriosis patients," Journal of Fujian College of Traditional Chinese Medicine, vol. 13, no. 4, pp. 21-23, 2003.
[125] H. M. Wang, P. Chen, S. Y. Feng et al., "Study of Cake-separated moxibustion on serum PGE2 levels in endometriosis rats," Chinese Journal of Traditional Medical Science and Technology, vol. 11, no. 6, p. 361, 2004.

[126] H. M. Wang, P. Chen, S. Y. Feng et al., "Study of Cake-separated moxibustion on serum 6-keto-PGF1 $\alpha$ levels in endometriosis rats," Shanghai Journal of Acupuncture and Moxibustion, vol. 23, no. 10, pp. 39-40, 2004.

[127] Q. Chen, G. P. Yue, and W. M. Zhang, "Clinical observation of acupuncture treatment on 27 endometriosis patients," Chinese Acupuncture \& Moxibustion, vol. 2, pp. 25-27, 1996.

[128] L. J. Mu, "Effect observation of 42 endometriosis patients treated with the treatment of acupuncture," Chinese Materia Medica, vol. 19, no. 12, pp. 80-82, 2012.

[129] H. Y. Lin, B. S. Xu et al., "Effect of acupoint injection with alarelin on SP expression and analgesia in rats of endometriosis model," Suzhou University Journal of Medical Science, vol. 29, no. 4, pp. 636-642, 2009.

[130] Q. F. Sun, "Treatment of 25 Ovarian chocolate cysts with Xiaoqiaotang and acupoint injection," Hunan Journal of Traditional Chinese Medicine, vol. 21, no. 5, pp. 62-63, 2012.

[131] X. L. Hui, Y. Zhang, and R. J. Dong, "The treatment of 38 endometriosis patients with Acupuncture and Chinese medicine," Journal of Shaanxi College of Traditional Chinese Medicine, vol. 32, no. 3, pp. 45-46, 2009.

[132] C. Q. Si, “The treatment of 58 endometriosis patients with Acupuncture and Chinese medicine," Hebei Journal of Traditional Chinese Medicine, vol. 34, no. 5, pp. 678-679, 2012.

[133] L. Zhang, "Clinical observation of Acupuncture and Herbs treatment for endometriosis," China Medical Herald, vol. 4, no. 16, p. 136, 2007.

[134] C. Q. Si, "Treatment of Acupuncture and Herbs for 58 endometriosis patients," Hebei Journal of Traditional Chinese Medicine, vol. 34, no. 5, pp. 678-679, 2012.

[135] Y. Fu and T. Xia, "Clinical observation of Acupuncture and Herbs treatment for endometriosis," Shanghai Journal of Acupuncture and Moxibustion, vol. 24, no. 3, pp. 3-5, 2005.

[136] Y.-F. Chen, C.-Y. Zhang, X.-Y. Zhang et al., "Effects of acupuncture combined with medicine on expression of matrix metalloproteinase-2 in the rat of endometriosis," Chinese Acupuncture \& Moxibustion, vol. 28, no. 9, pp. 675-680, 2008.

[137] X. B. Hua, R. C. Li, H. L. Zhou et al., "Development of rat acupuncture points map," Experimental Animals and Animal Experiments, vol. 1, pp. 1-5, 1991.

[138] Y.-B. Jin, Z.-L. Sun, and H.-F. Jin, "Randomized controlled study on ear-electroacupuncture treatment of endometriosis-induced dysmenorrhea in patients," Acupuncture Research, vol. 34, no. 3, pp. 188-192, 2009.

[139] D. F. Xiang, T. Y. Si, and S. G. Deng, "Affect of ear acupoint area electro-acupuncture on the endorphins and uterine activity in endometriosis model animals," Forum on Traditional Chinese Medicine, vol. 20, no. 4, pp. 46-47, 2005.

[140] S. P. Li, C. Liu, and G. M. Huo, "Effects of galvano-acupuncture Guanyuan and Diji on $\beta$-Endorphin and Dynorphin in endometriosis rats," Shaanxi Journal of Traditional Chinese Medicine, vol. 25, no. 3, pp. 49-50, 2009.

[141] H. M. Wang and Q. Wang, "The experimental research of compound dragon's blood and agent of acupoint sticking therapy endometriosis," Chinese Journal of Traditional Medical Science and Technology, vol. 15, no. 2, pp. 83-84, 2008. 
[142] Y. H. Duan, Y. H. Duan, and Y. H. Li, "The efficacy of auricular acupuncture treatment of primary dysmenorrhea and its impact on serum PGE-2," Zhejiang Journal of Traditional Chinese Medicine, vol. 42, no. 3, pp. 168-170, 2007.

[143] S. Y. Zhou, "Treatment of 64 endometriosis patients with enema," Guide of China Medicine, vol. 10, no. 4, pp. 226-229, 2012.

[144] H. Y. Wu, "Treatment of 33 endometriosis patients with infertility through Enema therapy," China Modern Doctor, vol. 47, no. 13, p. 77, 2009.

[145] L. Zhang and P. Q. Zhu, "Treatment of endometriosis through enema with Qingyitang," Journal of Sichuan of Traditional Chinese Medicine, vol. 25, no. 12, pp. 84-885, 2007.

[146] X. P. Lei, Z. P. Ye, and R. Li, "Introduction of microwave treatment principle," Progress in Physiological Sciences, vol. 33, no. 3, p. 286, 2002.

[147] B. Sharma, J. Preston, and C. Ray, "Microwave endometrial ablation for menorrhagia: outcome at 2 years-experience of a district general hospital," Journal of Obstetrics and Gynaecology, vol. 24, no. 8, pp. 916-919, 2004.

[148] Y. Kanaoka, K. Hirai, and O. Ishiko, "Successful microwave endometrial ablation in a uterus enlarged by adenomyosis," Osaka City Medical Journal, vol. 50, no. 1, pp. 47-51, 2004.

[149] M. B. Tang, S. M. Zhang, Y. J. Ding et al., "Clinical applied research on rectal uterine endometriosis treatment with microwave combined with traditional Chinese medicine," Journal of Practical Traditional Chinese Internal Medicine, vol. 26, no. 7, p. 66, 2012.

[150] K. Xu and J. C. He, "The treatment of 324 tubal infertility patients with Chinese Herbs combining enema microwave therapy," Chinese Community Doctors, vol. 23, no. 24, p. 36, 2007.

[151] Y. H. Sun and Y. Q. Sun, "Observation of 106 endometriosis patients treated with ZiniTuxie XiaozhengJian combining microwave physiotherapy," Information on Traditional Chinese Medicine, vol. 25, no. 4, pp. 41-42, 2008.

[152] X. H. Wu and C. L. Zhang, "The treatment for 49 endometriosis patients with Chinese herbal enema and Chinese medicine," Guangming Journal of Chinese Medicine, vol. 26, no. 12, p. 2467, 2011.

[153] H. H. Chen, "Clinical observation of traditional Chinese combining western medicine treatment for 45 endometriosis patients," Journal of Beijing University of Traditional Chinese Medicine, vol. 30, no. 9, p. 643, 2007.

[154] W. L. Li and X. J. Song, "Integrated traditional Chinese medicine treatment for 68 endometriosis patients," Modern Traditional Chinese Medicine, vol. 29, no. 3, p. 19, 2009.

[155] J. Yang, "Enema treatment for 50 endometriosis patients," Shaanxi Journal of Traditional Chinese Medicine, vol. 26, no. 10, p. 1007, 2005.

[156] B. J. Yu and Y. H. Zhao, "Clinical observation of endometriosis patients treated with Chinese medicine," Chinese Journal of Misdiagnostics, vol. 9, no. 9, p. 2055, 2009.

[157] K. Meissner, B. Böhling, and A. Schweizer-Arau, "Long-term effects of traditional chinese medicine and hypnotherapy in patients with severe endometriosis-a retrospective evaluation," Forschende Komplementarmedizin, vol. 17, no. 6, pp. 314320, 2010.

[158] R. S. Hawkins and A. D. Hart, "The use of thermal biofeedback in the treatment of pain associated with endometriosis: preliminary findings," Applied Psychophysiology Biofeedback, vol. 28, no. 4, pp. 279-289, 2003. 


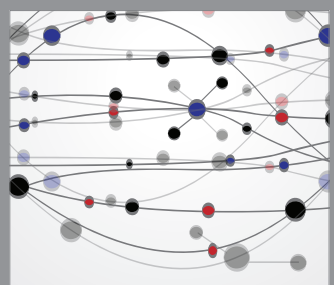

The Scientific World Journal
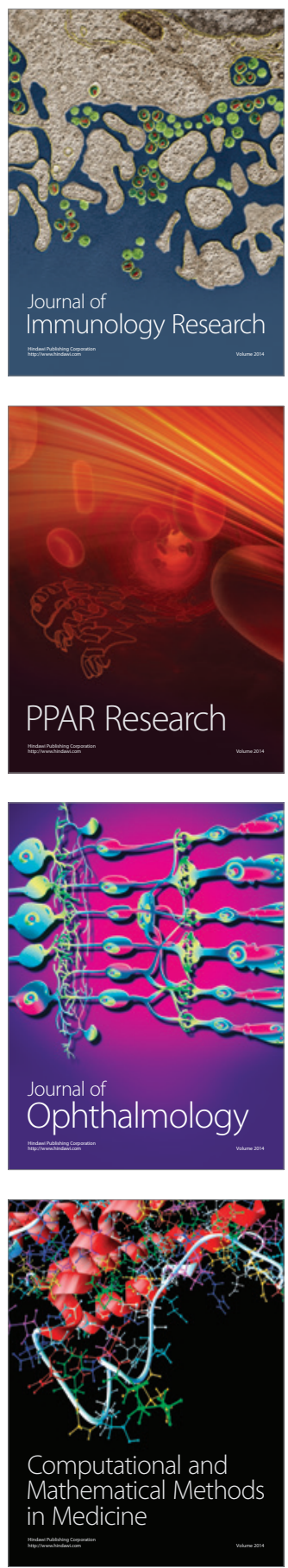

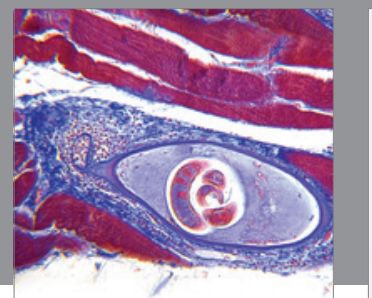

Gastroenterology

Research and Practice
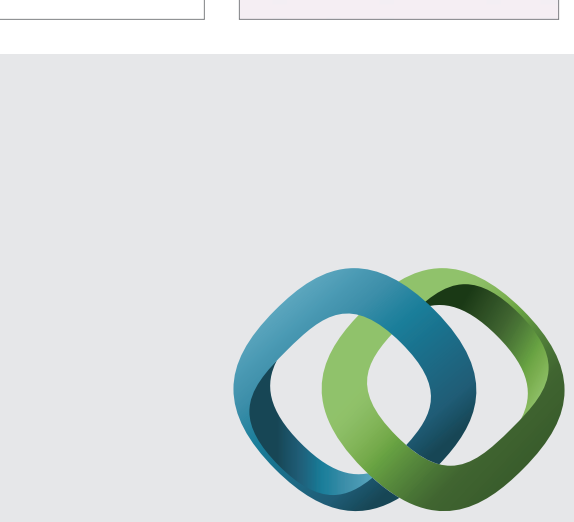

\section{Hindawi}

Submit your manuscripts at

http://www.hindawi.com
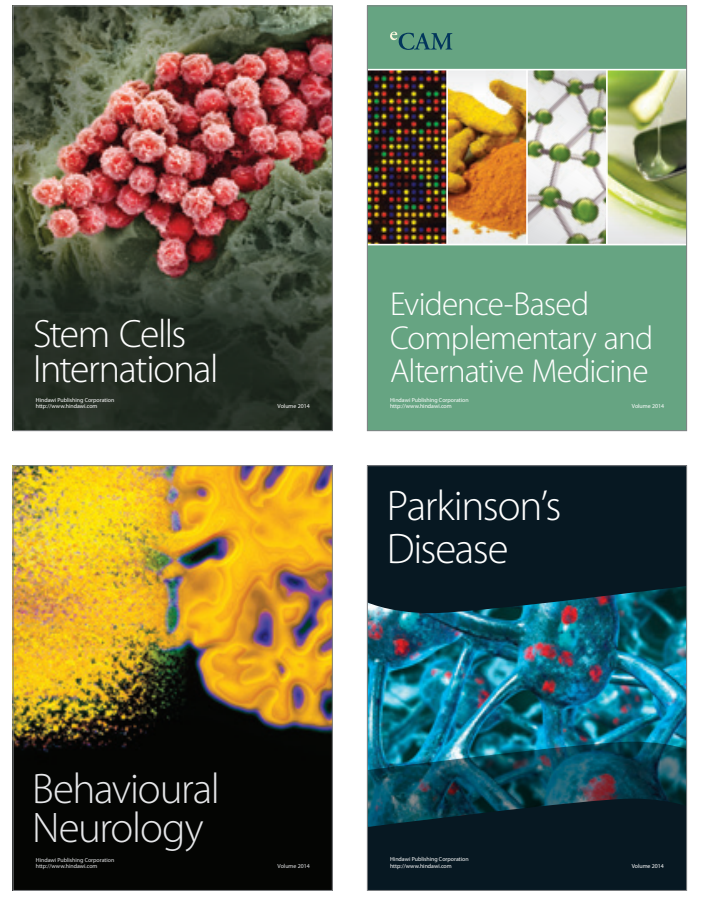
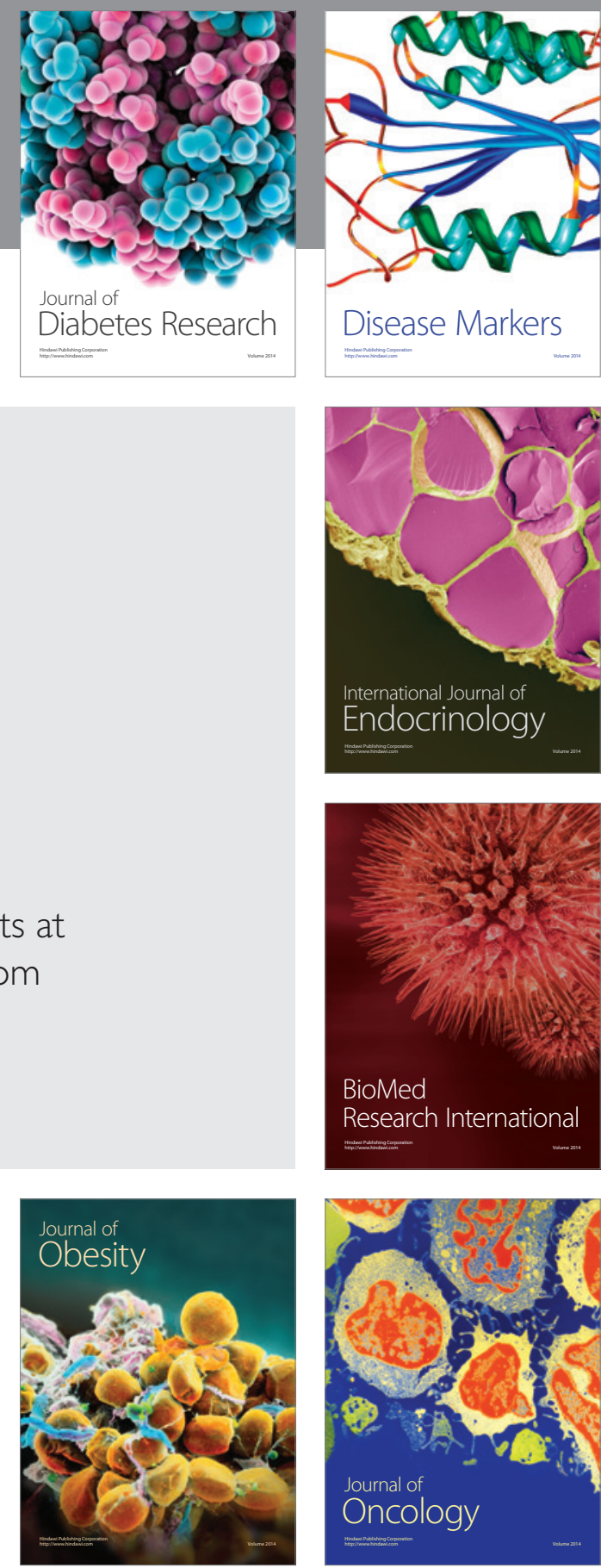

Disease Markers
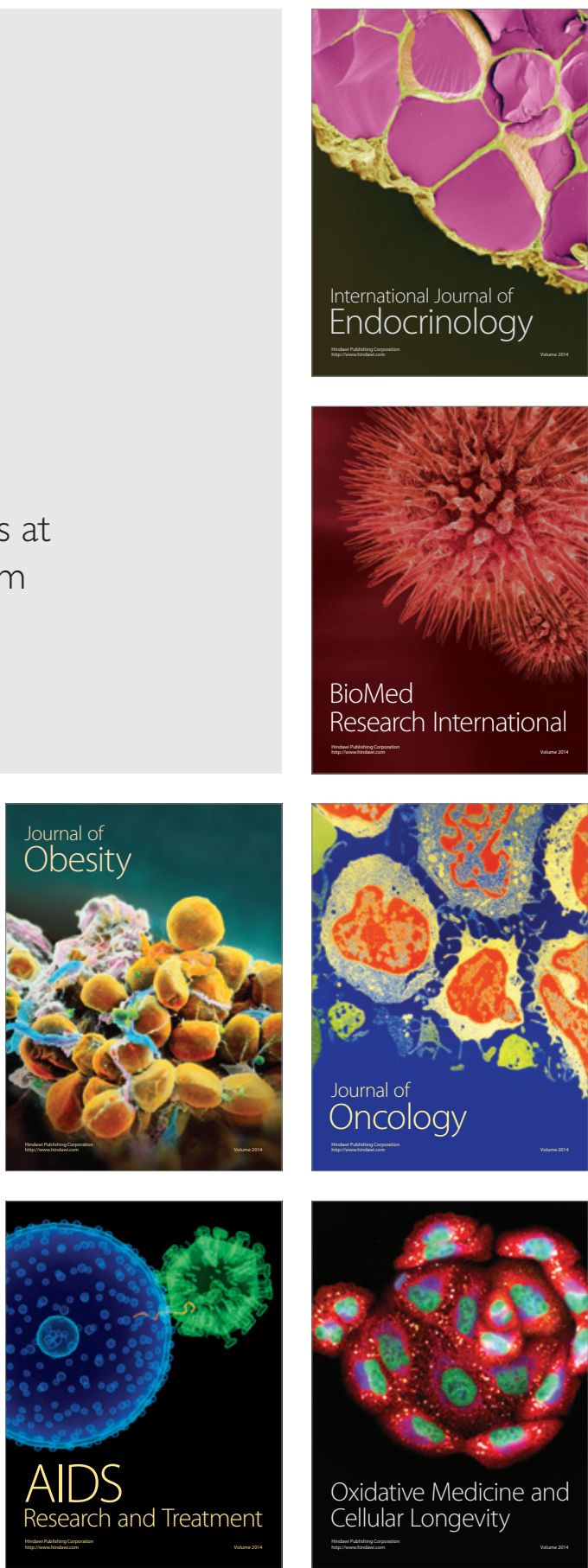